This revised manuscript - a preprint submitted to EarthArXiv - is in peer-review with the journal QUATERNARY SCIENCE REVIEWS.

Please note that the manuscript is under revision and subsequent versions of this research article may have a slightly different content.

If accepted, the final version of the manuscript will be available via the "Peer-reviewed Publication DOI" link on this webpage. 


\section{Environmental variability at the margin of the South American Monsoon \\ 2 System recorded by a high-resolution sediment record from Lagoa Dourada \\ 3 (South Brazil)}

4

Bernd Zolitschka*1, An-Sheng Lee ${ }^{1,2}$, Daniela Piraquive Bermúdez ${ }^{3}$, Thomas Giesecke ${ }^{3,4}$

${ }^{1}$ University of Bremen, Institute of Geography, Germany

${ }^{2}$ National Taiwan University, Department of Geosciences and Research Center for Future Earth, Taipei, Taiwan

${ }^{3}$ Department of Palynology and Climate Dynamics, University of Göttingen, Germany

${ }^{4}$ Department of Physical Geography, Utrecht University, The Netherlands

*Corresponding author: University of Bremen, Institute of Geography, Celsiusstr. 2, 28259 Bremen, Germany (E-Mail: zoli@uni-bremen.de)

\section{ORCID's}

BZ: https://orcid.org/0000-0001-8256-0420

ASL: https://orcid.org/0000-0002-5492-1986

DPB: https://orcid.org/0000-0002-7686-8135

TG: https://orcid.org/0000-0002-5132-1061

Keywords: hydroclimate, soil erosion, human impact, XRF scanning, geochemistry, Holocene, 8.2 ka event, 4.2 ka event, Little Ice Age, South American Monsoon System (SAMS)

\section{Abstract}

High-resolution geochemical and sedimentological data have been obtained for a lacustrine sediment record from Lagoa Dourada (South Brazil). Four distinctly different depositional processes were determined: (1) Suspension fallout of fine-grained minerogenic particles transferred via fluvial activity dominates the Early Holocene and relates to open grassland in the catchment area; (2) Activation of the karst hydrological system with deposition of massive sand layers indicates increased precipitation at the onset of the Middle Holocene; (3) Minerogenic sediments are replaced by organic deposition due to wetter climatic conditions with the expansion of woodlands in combination with release of dissolved nutrients due to enhanced pedogenesis during the Middle to Late Holocene; (4) Human-induced land-use change caused destabilization of soils in the catchment area with resulting cultural soil erosion between AD 1800 and 1950. These depositional trends are linked to intensity variations of the South American Monsoon System (SAMS). Century-long climatic events detected by data of high-resolution XRF scanning confirm this relationship and provide signals of the 
8.2 and 4.2 ka events as well as of the Little Ice Age. These events document increased rainfall with complex responses of the environmental system. Our SAMS-induced consequences of past hydroclimatic variability on the environment of South Brazil provide background information for better evaluating model projections of future climate change.

\section{Introduction}

Brazil is the country with the second largest forest cover in the world and thus provides an enormous potential for decarbonization initiatives through $\mathrm{CO}_{2}$ storage in biomass. Especially, the Amazon and the Atlantic rain forests belong to those regions on Earth with the richest biodiversity (Carnaval et al., 2009; Myers et al., 2000). Moreover, the Atlantic rain forest was and is very important for the economic development of Brazil. Where once forests were growing, there is today rapid industrialization hosting one of the most densely populated regions of South America. Most forests disappeared, with less than $10 \%$ remaining as fragmented woodlands. This has major consequences for regional climate, biodiversity and soil erosion (Freitas, 2011).

The Atlantic rain forest is a $4000 \mathrm{~km}$ long and $100-200 \mathrm{~km}$ wide band along the Atlantic coast of Brazil, from tropical Natal in the NE $\left(5^{\circ} \mathrm{S}\right)$ to subtropical Porto Alegre in the $\mathrm{S}\left(30^{\circ} \mathrm{S}\right)$. Its appearance is dependent on the spatial and temporal distribution of precipitation and climatologically controlled by the South American Monsoon System (SAMS) (Deininger et al., 2019; Zhou and Lau, 1998). Moreover, this is the most significant atmospheric circulation system of South America and responsible for precipitation from the Amazon to the La Plata Basin (Baker and Fritz, 2015). This large-scale climatic system is driven by differential heating of continents and oceans and responsible for seasonal reversals of low-level winds, a typical monsoon feature (Zhou and Lau, 1998). In southern winter, the Intertropical Convergence Zone (ITCZ) remains north of the equator, while SE Brazil is dominated by the South Atlantic high-pressure cell moving towards the continent. Thus, the advection of cold polar air masses closely linked to South Atlantic cyclones (SACs) brings humidity from the Atlantic Ocean to South America with coastal rainfall from $25-30^{\circ} \mathrm{S}$. At the same time, NE Brazil experiences a dry season of 6-8 months duration. This constellation changes in southern summer, when the ITCZ extends further to the south. Warm and moist tropical air masses from the Amazon Basin cause rainfall from $15-25^{\circ} \mathrm{S}$, while the Atlantic high-pressure cell is weakened and moves to an offshore position (Baker and Fritz, 2015; Ledru et al., 1998). Currently, $60 \%$ of precipitation is related to the summer monsoon (October-March) and $40 \%$ are considered as winter rain (Cruz et al., 2007). Most of the millennial-scale variability of the SAMS coincides with orbital forcing, i.e. variations of insolation, while minor influences are related to Southern Hemispheric Westerlies (SHW) and Atlantic sea surface temperatures (Baker and Fritz, 2015; Deininger et al., 2019; Utida et al., 2020). As the Atlantic rain forest depends on the amount of precipitation, orbitally controlled changes in precipitation are directly linked to its retractions and expansions but also to changes in vegetation types, i.e. from grasslands to woodlands and vice versa (Ledru et al., 2009; Novello et al., 2017).

Such climatic changes are not directly recorded in environmental archives but have to be inferred from the results of environmental processes acting under particular climate conditions. These proxy data are usually imperfect recorders of a small number and often not well constrained climate and environmental variables. In this regard, lake sediments are considered one of the most powerful terrestrial archives of past environmental and hydroclimatic variability. Such information is also an important contribution to the understanding of present ecosystems and their stability. Through a large number of proxies, lake sediment records have the potential to characterize their lacustrine system and the catchment area with natural and anthropogenic processes closely linked to regional hydroclimatic conditions. However, and due to the scarce occurrence of natural lakes in S and SE Brazil, only a limited number of such long-term environmental histories are available. Just three 
multiproxy studies were carried out on lacustrine sediments that include geochemical, sedimentological, diatom and/or stable isotope data and provide a more comprehensive picture of environmental processes: Lago Aleixo at $18^{\circ} \mathrm{S}$ (Enters et al., 2010), Lago Silvana at $19.5^{\circ} \mathrm{S}$ (RodriguesFilho et al., 2002) and Lagoa Dourada at $25^{\circ} \mathrm{S}$ (Melo et al., 2003; Moro et al., 2004). The majority of paleoenvironmental investigations carried out in this SAMS-dominated region are pollen and charcoal studies of small wetlands mainly from highlands and coastal mountains (Rodrigues et al., 2016) and only a small number of studies reconstructing Holocene and Late Pleistocene vegetation is based on lacustrine sediments (e.g., Behling, 1995, 2003; Behling and Safford, 2009).

The best available information on hydrological changes in S Brazil is provided by the speleothem records from Caverna Botuverá (Bernal et al., 2016b; Cruz et al., 2005). Their oxygen isotope records document a period of increased humidity during the Younger Dryas (YD), while the remainder of the Late Glacial and the Early Holocene were dry relative to present-day conditions. At that time, the vegetation on highlands and coastal mountains was dominated by grasslands with the Pleistocene/Holocene transition often marked by a shift in abundance of fern spores, possibly responding to the more humid YD (Behling and Oliveira, 2017; Behling et al., 2004). These relatively dry conditions of the Early Holocene caused hillslope denudation with silt-rich suspension deposits in lakes as reported e.g. for Lago Silvana (Rodrigues-Filho et al., 2002).

The oxygen isotope record indicates a shift to more humid conditions between 7000 and 4400 cal. BP (Bernal et al., 2016b; Cruz et al., 2009) and many pollen diagrams from S and SE Brazil indicate a gradual increase in woodland cover across the highlands (e.g., Behling et al., 2004; Jeske-Pieruschka et al., 2013). Thus, hillslope erosion was more and more reduced and chemical weathering increased leading to intensified pedogenesis with the leaching of nutrients. Consequently, the surplus of nutrients enhanced the biological productivity of lakes as documented by organic sediments e.g. for Lago Aleixo (Enters et al., 2010). A major spread of woodlands and in particular of Araucaria angustifolia in pollen diagrams started only after ca. 4300 cal. BP with marked increases at 2800 and $1200 \mathrm{cal}$. BP leading to the development of the modern mosaic of grasslands and Araucaria forests (Rodrigues et al., 2016). These conditions continued until the last millennium when few pollen records document even wetter climatic conditions, i.e. they are evidence for the Little Ice Age (LIA) (Behling, 2003; Behling et al., 2004). Finally, the vegetation was modified by agricultural activities of European settlers that started in the late $18^{\text {th }}$ century increasing thereafter (Freitas, 2011). In consequence, soil erosion was activated leading to deposition of more minerogenic sediments in some of the studied lakes (Enters et al., 2010; Portes et al., 2018).

Located at the southern fringe of SAMS influence, Lagoa Dourada is a promising site to enhance our understanding of Holocene climatic conditions with high-resolution environmental records. Initial low-resolution investigations are available, including palynological, diatom, total carbon, $\delta^{13} \mathrm{C}$, LOI550 as well as selected elemental (P, Ca, Mg, K) data (Lorscheitter and Takeda, 1995; Melo et al., 2003; Moro et al., 2004). However, the provided chronology is based on only two bulk radiocarbon dates from the Early Holocene, insufficient for a detailed understanding of paleoenvironmental changes. With this investigation, we provide new and high-resolution sedimentological and geochemical data to study hydroclimatic variations from a site located in a climatically sensitive region of S Brazil. Thirty years after first investigations at Lagoa Dourada have been carried out (Melo et al., 2003; Moro et al., 2004), this lake was re-visited and two long and overlapping sediment profiles were recovered. The major goal of this study focuses on the knowledge gap existing for lowand high-frequency environmental variability in SE Brazil climatically controlled by the SAMS. Moreover, we aim at providing detailed background information to better evaluate past climatic developments, which provide keystones for model predictions of future climatic conditions. To achieve this goal, we use sophisticated age-depth modeling based on radiocarbon-dated terrestrial macro remains and on bulk dates with reservoir correction, apply scanning techniques (X-ray fluorescence, magnetic susceptibility) as well as multiproxy sediment analyses to establish a 
continuous and high-resolution geochemical and sedimentological dataset for a better understanding of the responses of lacustrine and geomorphological systems to hydroclimatic variability.

Furthermore, anthropogenic impacts of the last two centuries are discussed that influence cultural soil erosion and lacustrine eutrophication. This is supported by high-resolution investigations of pollen and charcoal reliably linking vegetation and forest fires to climatic variations and human activities. Except for pollen and charcoal studies, which are discussed by Piraquive Bermúdez (2020) and will be published elsewhere, this investigation provides a comprehensive and well-dated multiproxy investigation allowing insights into geomorphological processes in the catchment area as well as into lacustrine processes, all reflecting hydroclimatic fluctuations in response to SAMS variability during the Holocene.

\section{Study Site}

Lagoa Dourada (Portuguese: Golden Lake) is located in Vila Velha State Park near Ponta Grossa $\left(25^{\circ} 14^{\prime} 25^{\prime \prime} \mathrm{S}, 50^{\circ} 02^{\prime} 59^{\prime \prime} \mathrm{W}, 817 \mathrm{~m}\right.$ asl) around $80 \mathrm{~km}$ W of Curitiba, the capital of the State of Paraná (S Brazil), and $180 \mathrm{~km} \mathrm{~W}$ of the Atlantic coast. The small lake has a maximum water depth of $5.4 \mathrm{~m}$ and is elliptical in shape with a size of ca. $150 \mathrm{~m} \times 200 \mathrm{~m}$ (Moro et al., 2004). It was formed in the Furnas Formation on the Second Paraná Plateau (Fig. 1). The Furnas Formation is of Silurian to Devonian age, part of the Paleozoic Paraná Sedimentary Basin, mainly consists of whitish, medium to coarse-grained quarzitic sandstones (Melo and Giannini, 2007; Pires et al., 2019) and is classified as quartz-arenite with $97 \%$ quartz (Pontes et al., 2020). Aside from mainly kaolinite as cement, these sandstones are enriched in ultra-stable minerals such as zircon (Moro et al., 2004). Chemical weathering of the cement as well as of quartz-grain surfaces by intergranular corrosion is responsible for the process of arenization, which loosens and removes sand grains by groundwater (Wray, 2013). Overall, arenization increases the underground porosity and finally causes the development of silicate karst.

The Vila Velha State Park was created in 1953 and is enlisted as a State Heritage since 1966 (Thomaz, 2010). It is famous for its karstic features in sandstone with caves, dolines, sinkholes, speleothems, karren, collapse structures and underground drainage systems including karstic springs (Melo and Giannini, 2007). The formation of quarzitic karst is very slow-acting compared to carbonaceous karst and requires extended periods of geological stability with intensive chemical weathering. As a consequence of subterranean karstic erosion, Lagoa Dourada was formed as a sinkhole after the roof of a cave collapsed. Such sinkholes (Portuguese: furnas) are typical for this part of the Paraná Basin and eponymous for the Paleozoic Furnas Formation.

As the non-fluvial catchment area of Lagoa Dourada is composed of siliceous karst, there is limited surface runoff into the lake: precipitation immediately infiltrates, contributes to the underground karstic drainage system and returns to the surface via layered karstic springs at the northern shores of Lagoa Dourada. There the Furnas Formation borders the alluvial plain of Rio Guabiroba. Petrographic data document that sands transferred via karstic springs are enriched in ultra-stable minerals like their source: the Furnas Formation (Melo et al., 2003).

The short and ca. 300 m-long outflow of Lagoa Dourada drains into Rio Guabiroba. However, during high rainfall events with flooding, the water in the outflow channel changes direction and enters the lake. These floodwater invasions are silting-up Lagoa Dourada from the $S$, while the largest water depth of the lake is close to the northern shore (Melo et al., 2003). During flooding, a much larger catchment area extends ca. $25 \mathrm{~km}$ towards E (Fig. 1). This watershed of Rio Guabiroba includes not only sandstones of the Furnas Formation but also shales and fine-grained sandstones of the Devonian Ponta Grossa Formation as well as reddish and predominantly medium-grained Vila Velha Sandstones of the Upper Carboniferous Itararé Group (Fig. 1). The latter is cemented by iron and 
manganese oxides and dominated by quartz with a high mineralogical maturity (Melo et al., 2003; Melo and Coimbra, 1996). Some of the strongly cemented parts of the Vila Velha Sandstone are resistant against weathering and form ruined inselbergs described as "ruiniform relief" (Melo and Coimbra, 1996), one of the major attractions of the Vila Velha State Park.

The subtropical climate at Vila Velha is characterized by temperate oceanic conditions without dry seasons ( $\mathrm{Cfb}$ according to the Köppen classification). The mean annual temperature is $17.5^{\circ} \mathrm{C}$ (warmest month January: $21.4^{\circ} \mathrm{C}$; coldest month July: $13.7^{\circ} \mathrm{C}$ ) and the annual sum of precipitation reaches 1495 mm (wettest month February: 177 mm; driest month August: 83 mm) (Merkel, 2020). Regional vegetation is dominated by subtropical grassland (Campos) with Araucaria woodlands covering hills and valleys (Moro and Fürstenberger, 1998). A recent vegetation map of the Vila Velha State Park determined Araucaria angustifolia (12\%) as the characteristic local tree in valleys and moister habitats with deeper soils, while on shallow and drier soils on sandstones Campos dominates with Poaceae (23\%), Cyperaceae (13\%), Asteraceae (10\%) and Baccharis (9\%) (Piraquive Bermúdez et al., 2021).

The modern freshwater of Lagoa Dourada is characterized by alkalinity of $77.5 \mathrm{mg} / \mathrm{l}, \mathrm{pH}$ of 7.8 , water temperature of $19.8^{\circ} \mathrm{C}$ and $9.2 \mathrm{mg} / \mathrm{l}$ dissolved oxygen. All measurements are mean August values obtained from the epilimnion of 1990-1993 (Moro and Fürstenberger, 1998). These water conditions are confirmed by modern diatom samples, which document eutrophic conditions typical for a shallow alkaline to neutral lake with a dominance ( $>90 \%)$ of periphytic over planktonic diatom species (Moro and Fürstenberger, 1998).

\section{Methods}

\section{Coring, lithological description and subsampling}

In February 2017 two parallel and overlapping sediment cores (LD17-A: to a sediment depth of 14.0 m; LD17-B: $14.2 \mathrm{~m}$ ) have been recovered. The upper $10 \mathrm{~m}$ were cored with a light-weight Livingstone piston corer (Nesje et al., 1987) and the deeper sediments with a square-rod Livingstone piston corer (Wright, 1967). The $1 \mathrm{~m}$ long core sections (diameter: $50 \mathrm{~mm}$ ) were obtained from a location south of the largest water depth $(5.4 \mathrm{~m})$ of Lagoa Dourada $\left(50^{\circ} 2^{\prime} 58.21^{\prime \prime} \mathrm{W} ; 25^{\circ} 14^{\prime} 25.55^{\prime \prime} \mathrm{S}\right)$. Coring sites were 10-15 $\mathrm{m}$ apart and at $4.0 \mathrm{~m}$ (LD17-A) and $2.8 \mathrm{~m}$ (LD17-B) water depths (Fig. 1). The upper $20 \mathrm{~cm}$ of the record were almost liquid, difficult to retain and only used for pollen analysis. All sediment cores were shipped to the University of Göttingen, where they were split, photographed and described macroscopically. In addition, 14 smear slides from characteristic intervals were prepared following Rothwell (1989) for microscopic sediment description (magnification: 100-400 x) at the University of Bremen. In support of core description, high-resolution color images are available from the line-scan camera mounted to the ITRAX X-ray fluorescence (XRF) core-scanner (Croudace et al., 2019; Croudace et al., 2006).

Subsampling for pollen (Piraquive Bermúdez, 2020) and in parallel for sedimentology and geochemistry (this study) was carried out providing a total of 177 samples with a mean spatial resolution of $8 \mathrm{~cm}$.

\section{Dating}

Terrestrial plant macro remains, encountered during subsampling and searched for by sieving sediment slices, were preferably used for radiocarbon dating wherever possible. However, no macroscopic plant remains were found below $7.31 \mathrm{mcd}$ (meter composite depth), except for a part of a twig at $9.24 \mathrm{mcd}$. Twenty-one AMS ${ }^{14} \mathrm{C}$ samples were dated at the Poznań Radiocarbon Laboratory in Poland (POZ) and two additional samples at the ${ }^{14}$ Chrono Centre, Queen's University Belfast in 
Northern Ireland (UBA). Eight dates derive from terrestrial plant macro remains, while other determinations are based on bulk organic matter (OM; Tab. 1). To assess the magnitude of a presumed old carbon effect of bulk dates (reservoir effect), two sediment samples were submitted for radiocarbon dating above and below the terrestrial macrofossil date at $7.31 \mathrm{mcd}$. These two dates were not used in building the age model. In addition to the radiocarbon dates, the sediment/water interface (AD 2017) is used as a control point, while distinct sand sections in the core are interpreted as events and treated as instantaneous. Sediment accumulation in relation to the results of radiocarbon measurements and the core top was modelled using the R-package "rbacon" (Blaauw et al., 2021). Radiocarbon dates were calibrated during age modelling applying the Southern Hemisphere calibration curve SHCal20 (Hogg et al., 2020).

Several publications used for discussion provide only uncalibrated radiocarbon ages. To improve comparisons with our data, these ages were calibrated using OxCal 4.4 (Bronk Ramsey, 2009) applying the Southern Hemisphere calibration curve SHCal20 (Hogg et al., 2020).

\section{Core scanning}

Prior to applying non-destructive core scanning techniques, the split core halves were cleaned and increments with a Bartington MS2E sensor employed to an automated measuring bench (Dearing, 1994; Nowaczyk, 2001). For analyzing the geochemical composition of sediment cores in high resolution, all sections were scanned with the ITRAX XRF core scanner (Cox Analytics) (Croudace et al., 2019; Croudace and Rothwell, 2015). The molybdenum (Mo) tube was used with constant settings of $30 \mathrm{kV}$ and $50 \mathrm{~mA}$, a step size of $2 \mathrm{~mm}$ and an exposure time of $5 \mathrm{~s}$. The output was processed with the software Q-spec (Cox Analytics) and results are expressed in counts (cts), which describe relative intensities of 23 elements as well as variations of coherent (coh) and incoherent (inc) scattering.

In a next step, reproducibility of XRF elemental data was evaluated by five repeated scans of two $1 \mathrm{~m}$ long sections representing highly organic (sediment core LD17-B6) and highly minerogenic (LD17B12) sediment with the same adjustments as mentioned above. A feasible way to evaluate the credibility of each determined element is to calculate correlation coefficients for elements between replicate measurements where high correlations indicate good reproducibility for the respective element. This procedure allows excluding elements with low signal-to-noise ratios (Löwemark et al., 2019), thus reducing the number of elements for statistical evaluation.

Due to changing physical properties along the sediment record, like matrix effects related to variations in water content, OM content and/or grainsize, the chemical composition obtained by XRF core scanning is non-linearly correlated to element concentrations (Croudace et al., 2019; Tjallingii et al., 2007). Moreover, element intensities underlie the closed-sum effect, which inhibits multivariate statistical analyses (e.g., Martin-Puertas et al., 2017). A solution for these limiting factors is available with the centered log-ratio (clr), which normalizes data and determines relative changes in element composition resembling their chemical composition (Tjallingii et al., 2007; Weltje et al., 2015; Weltje and Tjallingii, 2008). Moreover, clr transformation is consistent with the statistical theory of compositional data analyses (Aitchison, 1982; Weltje et al., 2015) and calculates as:

clr of $I_{i j}=\ln \left(l_{i j} / g m_{j}\right)$,

where $\mathrm{I}_{\mathrm{ij}}$ is the intensity $(\mathrm{I})$ of the element $\mathrm{i}$ for measurement $\mathrm{j}$ and $\mathrm{gm}_{\mathrm{j}}$ is the geometric mean of all elements analyzed at measurement $\mathrm{j}$. In addition to elemental clr values, we calculate the log molybdenum incoherent/coherent scattering ratio (In inc/coh), which is regarded as a proxy for OM content of lacustrine sediments (Liu et al., 2013; Woodward and Gadd, 2019). This ratio of Compton scattering (inc) versus Rayleigh scattering (coh) depends on the presence of light elements $(H, C, N$, O). High amounts of these elements, such as analyzed for OM and/or high-water content, increase 
the Compton Effect and thus the value for In inc/coh. Other possible matrix effects are negligible (Weltje and Tjallingii, 2008; Woodward and Gadd, 2019).

Total carbon (TC), total nitrogen (TN) and total sulphur (TS) were measured with a CNS elemental analyzer (EuroEA, Eurovector). Prior to measurements, all 177 samples were freeze-dried, ground, homogenized and 5-20 mg were weighted into tin crucibles. During measurements, the elemental analyzer combusts the crucibles with the sample material at a temperature of $1800^{\circ} \mathrm{C}$. All OM is oxidized and the resulting gases $\left(\mathrm{CO}_{2}, \mathrm{NO}_{2}, \mathrm{SO}_{2}\right)$ are detected by chromatography. As TC includes organic as well as inorganic carbon, a second step is necessary to distinguish total organic carbon (TOC) from total inorganic carbon (TIC). As the catchment area has no carbonaceous rocks, we assume that also the lacustrine sediments are carbonate-free. To test this hypothesis, 10 samples with TC values $>2 \%$ were treated first with $3 \%$ and then with $20 \% \mathrm{HCl}$ at $80{ }^{\circ} \mathrm{C}$ to remove potential carbonates prior to measurement of TOC with the same elemental analyzer. Total inorganic carbon (TIC) was then calculated as the difference between TC and TOC. Furthermore and to distinguish autochthonous from allochthonous sources of $\mathrm{OM}, \mathrm{C} / \mathrm{N}$ ratios were calculated with low values $(<10)$ indicative of autochthonous lacustrine productivity (algal matter), while higher values (>20) are dominated by higher plants with cellulose of terrestrial origin (Meyers and Teranes, 2001). Biogenic matter is calculated as the sum of opal (BSi) and OM, which is the product of TOC with the factor of 2.13 (Dean, 1974).

Biogenic silica (BSi) was analyzed for 177 samples following the leaching method of Müller and Schneider (1993). We extracted BSi with $1 \mathrm{M} \mathrm{NaOH}$ at $85^{\circ} \mathrm{C}$. The solution was cycled by a continuousflow system into an auto analyzer, where dissolved silicon was detected by spectrophotometry.

Grainsize

Prior to grainsize analysis, $\mathrm{OM}$ was removed by $\mathrm{H}_{2} \mathrm{O}_{2}$ from each of the 177 samples. For dispersion, $20 \mathrm{ml}$ of Calgon [( $\left.\mathrm{NaPO}_{3}\right) \mathrm{n}$ ] was added and agitated overnight. On the next day, analyses were performed with a laser diffraction analyzer (Beckman Coulter LS 200) after ultrasonic treatment for $30 \mathrm{~s}$. Each sample was measured at least four times for $60 \mathrm{~s}$ until a stable distribution was reached. Thereafter, the arithmetic mean was calculated for the best three sample runs. Grainsize distributions and all statistical grainsize parameters were calculated from the output of the LS 200 as geometric graphical measures according to Folk and Ward (1957) with the MS Excel-based macro Gradistat, Version 8.0 (Blott and Pye, 2001).

$\underline{\text { Multivariate statistics }}$

Principal component analysis (PCA) was applied to the standardized and normalized (clrtransformed) dataset obtained by XRF core scanning for reducing the data dimension (Abdi and Williams, 2010). The standardization rescaled each element's profile to zero mean and unit standard deviation. The selection of credible principal components (PCS) is based on the elbow concept and preference is given to PCs with $>10 \%$ of total variance. The first two PCs were selected and whitened (i.e., standardized) as data representation. The logic of whitening is the same as for standardization prior to PCA. The process of whitening gives the two selected PCs equal contribution for later clustering. We applied "hierarchical density-based spatial clustering of applications with noise" (HDBSCAN). This clustering algorithm combines hierarchical clustering with the spatial density metric of data and tends to find clusters with dense distributions (Mclnnes et al., 2017). Due to densitybased characteristics, the shapes of the clusters are not limited to sphere-like shapes but can also be polygons as long as data points within these clusters are dense enough. Furthermore, data points located in a loose manner or at distance from the cores of dense clusters will be recognized as noise, i.e. as outlying data. This makes the algorithm robust against noise. HDBSCAN's hierarchical clustering approach on density metric provides flexibility with regard to density. In other words, data 
points determined as dense clusters can be based on different densities, for details see the algorithm's source documents (https://hdbscan.readthedocs.io/en/latest/index.html). Two primary parameters have to be adjusted for this algorithm. Min_cluster_size sets the minimum size for the grouping of data considered as a cluster and Min_sample determines what the algorithm defines as "dense", i.e. how many data points will be selected as noise. A grid search for optimal parameters (min_cluster_size: $20,50,80,100,150,200$; min_sample: $2,3,4,5,8,10$ ) was carried out by checking the visualization of spatial data distributions on the first two PCs. Optimal min_cluster_size and min_sample were set to 100 and 5, respectively. Computations and part of visualizations were conducted using the packages in the Scipy ecosystem (Harris et al., 2020; Hunter, 2007; Pedregosa et al., 2011; van der Walt et al., 2014; Virtanen et al., 2020) and the HDBSCAN library (Mclnnes et al., 2017).

Individual cluster labels were smoothed to develop the clusterlog. This was carried out by looking at subsets of 11 consecutive data points $(11 \times 2 \mathrm{~mm})$. For each of these subsets, fragmented labels and labels of minor importance were replaced by the dominant label. Thus, $31.4 \%$ of noise was changed to cluster labels, which increased the number of cluster labels for all clusters except for cluster 3 , which remained unchanged.

\section{Results}

\section{Core correlation and lithological description}

Correlation of core sections from LD17-A and LD17-B is based on 20 marker layers clearly distinguishable on high-resolution line-scan images and supported by high-resolution XRF core scanning data. Of all detected elements, $\mathrm{Ca}$ is best suited for this purpose due to relatively high counts combined with sufficient variability along the entire record (Fig. S1). All depths of the established composite record are provided in meter composite depth (mcd). Technical gaps due to coring typically occur between individual core sections and were bridged down to 10.5 mcd by parallel and overlapping cores (Fig. 2). Beyond $10.5 \mathrm{mcd}$ and until the basal depth of 14.4 mcd there are five intersections of which four could not be bridged due to lacking overlap. These gaps were assumed to be $3 \mathrm{~cm}$ wide based on the mean for similar technical gaps observed in the upper $10 \mathrm{~m}$.

Initially, the scans of magnetic susceptibility $(\chi)$ were intended for core correlation. However, the variability of $\chi$ was too low for this purpose (Figs. 3, S2). Moreover and above 9.7 mcd, LD17-A and LD17-B show mean values for $\chi$ of $-4.14 \mathrm{SI}$ and $-3.9810^{-6} \mathrm{SI}$, respectively, i.e. in the field of diamagnetism. Only below $9.7 \mathrm{mcd} \chi$ has positive mean values of $7.5110^{-6} \mathrm{SI}$ for LD17-A and 15.43 $10^{-6} \mathrm{SI}$ for LD17-B, i.e. in the field of paramagnetism (Fig. S2). Thus, the record of Lagoa Dourada carries no ferromagnetic signal and $\chi$ cannot be used for core correlation.

A test for total inorganic carbon (TIC) was carried out with 14 lithologically representative samples (Fig. 3). The detected values are very low and range between -1.99 and $2.49 \%$ TIC (mean: $0.45 \%$ TIC) confirming our assumption that the sediment is basically free of carbonates like the catchment area.

Based on macroscopic as well as on microscopic sediment characterization and supported by bulk geochemistry and grainsize, the sediment record of Lagoa Dourada is subdivided into seven lithological units (lithozones A to G: LZ A-G) with six subzones (Figs. 2, 3). Basal LZ A1 (14.4-12.1 mcd) is a dark gray mud composed of up to $15 \% \mathrm{BSi}$ (opal of small planktonic central and pennate diatoms as well as few sponge spicules) but low amounts of TOC ( 3 \%) in a silt-rich matrix. The $\mathrm{C} / \mathrm{N}$ ratio decreases from base (15) to top (10) of LZ A1, indicating increasing autochthonous OM supply. This development is interrupted by a gray layer of fine sand (LZ B1: 12.1-12.0 mcd) with almost no organic components. The following LZ C consists of laminated and diatomaceous dark gray mud (12.0-11.5 mcd) with dominating pennate and very small (planktonic) diatoms. C/N ratios remain low (7-12) and 
medium silt dominates the grainsize. Altogether, this evidences the development of a deeper lake system with peaking BSi (up to $30 \%$ ) and increasing TOC values ( 5 \%). LZ B2 (11.5-10.4 mcd) is a thick and structureless gray sand layer without organic components. With LZ A2 (10.4-10.0 mcd) the dark gray mud of LZ A1 returns. Compared to LZ A1, geochemical data of LZ A2 show markedly lower values for $\mathrm{BSi}(<3 \%)$, while TOC increases to $7 \%$ including more allochthonous organic material as indicated by rising $\mathrm{C} / \mathrm{N}$ ratios. For the third intercalation of gray sand (LZ B3: 10.0-9.5 mcd) inorganic conditions recur with $\mathrm{BSi}$ and TOC documenting almost absence of OM.

With the advent of LZ D1 (9.5-8.9 mcd), sediments change markedly (Fig. 3). The bedded brown organic mud differs distinctly from all lithozones below. A color change to brownish hues indicates an increased importance of OM (mean TOC $10 \%$ ) including plant macrofossils that explain the rise of $\mathrm{C} / \mathrm{N}$ ratios to 32. Diatoms show comparable values ( $3 \% \mathrm{BSi}$ ) like in $\mathrm{LZ} \mathrm{A2.} \mathrm{In} \mathrm{addition} \mathrm{to} \mathrm{changes} \mathrm{in}$ color and $\mathrm{OM}$, mean grainsize coarsens from dominance of medium silt in lithozones $A$ and $C$ to coarse silt in LZ D with frequent intercalations of fine sand. LZ D1 is followed by an intercalation of $1.2 \mathrm{~m}$ of dark gray sand (LZ E1: 8.9-7.7 mcd) consisting mainly of fine sand without organic components. Following this sand layer, sediments continue with LZ D2 (7.7-6.7 mcd) and increasing TOC values (20\%). Diatoms remain at lower values ( $3 \% \mathrm{BSi}$ ) like before, while $\mathrm{C} / \mathrm{N}$ ratios decrease to 20. After a second dark gray and fine sand horizon without organic components (LZ E2: 5.7-5.3 mcd), bedded brown organic mud (LZ D3: 5.3-1.1 mcd) continues with increasing OM contents (maxima up to $30 \% \mathrm{TOC}$ ) and slightly more diatoms ( $5 \% \mathrm{BSi}$ ), while $\mathrm{C} / \mathrm{N}$ ratios decrease to 13 . Throughout LZ D the mean grainsize remains in the coarse silt fraction, while organic productivity increases as documented by higher TOC and BSi values. At the beginning of LZ D3 the influence of allochthonous OM is still high $(C / N>20)$ but decreases thereafter to $<15$. In LZ D3 amorphous OM is ubiquitous as well as pyrite, which often forms microscopically detectable framboids.

With LZ F (1.1-0.4 mcd) minerogenic sediments recur (Fig. 3). This pale brown to gray clay-rich mud displays a drop in lacustrine productivity to $2 \% \mathrm{BSi}$ and $13 \%$ TOC (Fig. 3). Additionally, C/N ratios decline reaching low values of 11 , thus indicating dominance of autochthonous OM. Grainsize changes to finest values of the record with a mean in the fine silt fraction and up to $33 \%$ of clay. Finally, at the top of the record there is black, organic-rich and homogenous mud (LZ G: 0.4-0.2 mcd) with a higher water content and TOC values reaching $29 \%$, while the $\mathrm{C} / \mathrm{N}$ ratio remains at $\sim 10$. Despite these productive conditions causing highly organic sediments, BSi remains $<3 \%$.

\section{XRF scanning data: comparing litholog with clusterlog stratigraphies}

The XRF scanner detected 20 elements (Al, Si, P, S, Cl, K, Ca, Ti, V, Cr, Mn, Fe, Ni, Cu, Zn, Br, Rb, Sr, Zr, $\mathrm{Pb}$ ) with counts varying from $7(\mathrm{Cl})$ to 21,607 ( $\mathrm{Fe}$ ) as well as coherent (coh) and incoherent (inc) radiation. Many of these elements have low signal-to-noise ratios and need to be excluded from further discussion. Five replicate XRF scans were carried out for $97 \mathrm{~cm}$ of organic sediment from LD17-B6 (LZs D2, E2 and D3) and $97 \mathrm{~cm}$ of minerogenic sediment from LD17-B12 (LZs A1, B1 and C). These records were used in correlation analyses to inform on the replicability of the signals. High correlations reveal a generally good reproducibility of elemental analyses (Tab. S1). Only elements with a high positive correlation $(r>0.8)$ for at least one of the two scanned sediment sections are considered for further discussion (Tab. S1). Thus, ten elements ( $\mathrm{Si}, \mathrm{S}, \mathrm{K}, \mathrm{Ca}, \mathrm{Ti}, \mathrm{Fe}, \mathrm{Zn}, \mathrm{Rb}, \mathrm{Sr}, \mathrm{Zr}$ ) as well as the inc/coh ratio are selected for principal component analysis (PCA) and cluster analysis.

The first two principal components (PCS) are representing $64.6 \%$ of the explained total variance (Fig. 4). Additional PC's explain $<10 \%$ and were not considered based on the elbow concept (Fig. S3). This first PC discriminates with $43.8 \%$ of explained variance between organic (positive direction) and minerogenic sediment composition (negative direction). The second PC with $20.8 \%$ of explained variance represents mainly the trends in grainsize variability with larger grainsizes related to the positive direction and smaller grainsizes to the negative direction. Hierarchical density-based spatial clustering of applications with noise (HDBSCAN) provides four distinct clusters (Fig. 4), which are transferred into a clusterlog to be compared with the litholog (Fig. 2). Although the number of 
clusterlog units (4) is smaller than the number of litholog units (7), an overall agreement is evident. The discrepancies, i.e. merging of the LZs A with C, B with E as well as D with $G$, are related to XRF analyses capturing only heavier elements than Al. Thus, changes in organic sediment components consisting of lighter elements such as $\mathrm{H}, \mathrm{C}$ and $\mathrm{O}$ are not detected.

Cluster 1 combines LZ B (light gray sand) with LZ E (dark gray sand), the latter being influenced by organic-rich pore water available from under- and overlying highly organic sediments of LZ D. The distinct link to $\mathrm{Si}$ and $\mathrm{Zr}$ relates these two sandy lithozones to weathering resistant minerals (quartz, zircon) of the Furnas Formation as their source rock. LZ A (dark gray mud) and LZ C (laminated and diatomaceous dark gray mud) together are related to cluster 2, which shows $\mathrm{K}, \mathrm{Ti}$ and $\mathrm{Rb}$ as dominant siliciclastic elements. These elements likely originate from the Ponta Grossa Formation consisting of shales as potential source rocks.

Cluster 3 links to LZ F (reddish brown clay-rich mud) with Fe and Sr as dominant elements. As Fe is lacking in the Furnas Formation, these sediments derive from the iron-rich cement of the Vila Velha Sandstone. Moreover, PC loadings of Fe plot at the transition from minerogenic to organic components (Fig. 4), which indicates that Fe is not only bound to detrital silicates but also occurs as pyrite (FeS) and thus can as well be related to organic productivity. Sulphur is introduced to the sediment via lacustrine production of $\mathrm{OM}$, which is deposited, decomposed and combined with dissolved Fe under anoxic (reducing) conditions typical for eutrophic lakes. Thus, there is a positive correlation between Fe and S for organic LZ D $(r=0.49)$. However, the correlation for minerogenic LZs $A$ and $C$ is negative $(r=-0.48)$. This characteristic of Fe results in absence of any correlation between Fe and $S$ if the entire record is considered $(r=-0.20)$.

In cluster 4, including LZs D (bedded brown organic mud) and G (black, organic-rich homogenous mud), the organic components $\mathrm{S}, \mathrm{Ca}$ and the inc/coh ratio are combined. Despite this link to cluster 4, $\mathrm{Ca}$ has a positive correlation with the siliciclastic elements $\mathrm{K}(\mathrm{r}=0.68), \mathrm{Fe}(0.50), \mathrm{Rb}(0.68)$ and $\mathrm{Sr}$ (0.75) for LZs A1 and C. More dominantly than Fe, Ca is related to organic productivity, which might result from carbonaceous shells, which have been observed sporadically during coring. However, evidence for carbonate is lacking - TIC was not detected and XRD analysis is not promising because of very low calcite concentrations, as it was similarly documented for the highly organic sediment record from Laguna Azul (Zolitschka et al., 2019). Finally, the inc/coh ratio has a positive correlation $(r=0.88)$ with TOC (Fig. S4) and thus provides a very high-resolution record of OM for the sediment record of Lagoa Dourada.

\section{XRF scanning data: stratigraphy of selected elements}

447

448

449

450

451

452

453

454

455

456

457

458

459

460

461
High-resolution XRF core-scanning data support the lithological description. However, and due to their high spatial resolution of $2 \mathrm{~mm}$, XRF records are more detailed and provide additional insights. All sand layers are reflected by distinct lows of the $\mathrm{In}$ inc/coh ratio as well as by pronounced peaks in $\mathrm{Si}$ (Fig. 5), both proxies clearly document inorganic quartz deposition. The high-resolution OM proxy (In inc/coh) displays a steady increase of organic productivity from the base of LZ A1 until the top of the record, if the sand layers and LZ F are taken out of consideration. However, a marked increase is observed at the onset of LZ D1, when dark gray mud changes to brown organic mud. This distinct sedimentological transition is even more pronounced for the $S$ record, with low values prior to LZ D1 and much higher values during LZ D1 (Fig. 5). After this major sedimentological transition S covaries with $\mathrm{Fe}$, which is explained by diagenetic formation of pyrite (FeS). This mineral is formed under anoxic conditions and was determined by microscopic smear slide investigations as typical framboids. Such conditions also explain the higher degree of OM preservation during LZ D. During LZs A and C, Fe displays a decreasing trend and no covariation with $\mathrm{S}$. Thus, we consider Fe as being related to a siliciclastic source for the older part of the record. This assumption is supported by the elements $\mathrm{K}$ and Ti. Both are siliciclastic and decrease as well during LZs A and C (Fig. 5). 
The only marked change in the upper $5 \mathrm{~m}$ of the sediment record is related to the reddish-brown clay-rich mud of LZ F. During this lithozone, the organic parameters In inc/coh and S drop to distinctly lower values while Fe increases. We consider this as the result of an increased siliciclastic origin of $\mathrm{Fe}$ during $L Z F$, which is again supported by $K$ and Ti values rising in parallel. For topmost $L Z G$, most elemental parameters seem to continue from where LZ D3 was interrupted by LZ F. Only the element $K$ shows an unexpected increase during this lithozone peaking at higher values than during the entire LZ D.

\section{$\underline{\text { Grainsize statistics and sediment dynamics }}$}

Grainsize analysis documents two distinctly different populations (Fig. 6). Silty sand and fine to medium sand of LZs B and E are moderately well-sorted, unimodal and with one maximum in the fine sand fraction (Fig. S5). The other lithozones except LZ D3 consist of poorly sorted sandy silt or silt. They are characterized by bimodal grainsize distributions (Fig. S5) with maxima in the medium to coarse silt fractions and in the fine sand fraction (LZs A1 and F). Only LZ D3 displays a trimodal grainsize distribution with a broad maximum in the fine silt fraction and two narrow maxima in the fine and medium sand fractions (Fig. S5).

As there are no dunes or sand sheets in the catchment area to explain the moderately well-sorted sands of $L Z s B$ and $E$, we consider that this distinct unimodal grainsize distribution is inherited from sandstones of the Furnas Formation. During its relatively rapid flow through the karst hydrological system, the groundwater adds no additional grainsize fractions prior to deposition in Lagoa Dourada. Very different from the sand layers, the silt-sized sediment of LZs A, C and F probably originate from the shales of the Ponta Grossa Formation in the larger catchment area, which is drained via Rio Guabiroba and enters the lake during flooding events where it settles out of suspension. As this suspension freight needs to be transported towards the lake against the slope of the outlet channel (Fig. 1), it is unlikely that the fine sand component observed by the secondary grainsize maximum rained out of suspension from river floods as well. Instead, we consider these sands as subordinated contribution from karstic springs, contributions which are coarser and more pronounced during LZs A and $D$ compared to LZs $C$ and $F$. Lithozone $F$ has distinctly less fine sand, while there is a four-times higher contribution of clay.

Grainsize distributions provide insights into depositional processes at Lagoa Dourada. The two different sand horizons (LZs B and E) can only be differentiated by their color (Fig. 2), but have comparable unimodal grainsize distributions (Fig. S5) and an almost identical chemical composition (Figs. 4, 5). Based on the lack of OM and iron as well as on grainsize and chemical composition inherited from weathering-resistant minerals of the Furnas Formation, we consider these sands as event deposits related to flushing of the karst hydrological system. These sediments are added to the stratigraphic record in relatively short time intervals and thus are without temporal significance for the stratigraphic record. The other lithozones are dominated by silt-sized grainsize fractions, derived from suspension fallout, but also show a minor sandy component (bimodal grainsize distribution, Fig. S5) likely added by karstic springs. This sand component is least pronounced for LZs C and F. The highly organic LZ D shows a trimodal grainsize distribution (Fig. S5) with two maxima in the sand fraction, which is interpreted in terms of increasing importance of the karst system for the contribution of minerogenic components to the lake, while settling out of suspension was reduced.

\section{$\underline{\text { Age-depth model }}$}

All radiocarbon dates from terrestrial macrofossils are in stratigraphic order and their age-depth relationship is almost linear (Tab. 1, Fig. 7). Radiocarbon age determinations on bulk sediment also follow a linear age-depth trend with a cluster of three dates being too young and two dates being too old compared to the trend indicated by the other ten bulk dates. The two radiocarbon dates on bulk sediment above and below the terrestrial macrofossil at $7.3 \mathrm{mcd}$ are too old by 5065 and 5235 radiocarbon years, respectively (Tab. 1). The resulting average of 5150 years is used as an offset 
applied to all bulk dates prior to calibration. Describing the uncertainty of this reservoir correction, an error of 100 years was added as contribution of old carbon to the sediment, which cannot be regarded as constant with time.

The resulting age-depth model suggests an age of 10,400 cal. BP for the basal sample (Fig. 7). The two aforementioned clusters of five bulk dates deviating from the general trend were not considered by the age model. It is noticeable that four out of five bulk dates deviating from the linear trend were obtained from sand sections. The radiocarbon date of the twiglet at $9.25 \mathrm{mcd}$ was also compared to a neighboring bulk date resulting in an offset of 5145 years (Tab. 1), which confirms that the reservoir effect applied (5150 years) is applicable also for the older part of the record with much lower OM content.

\section{Interpretation}

Processes of sediment formation at Lagoa Dourada are differentiated into three modes according to their elemental composition and supported by cluster analysis (Figs. 3-5). The three involved depositional processes relate to (1) fluvial activities of Rio Guabiroba, (2) discharge through the karst hydrological system and (3) autochthonous lacustrine productivity. Contributions of all three processes vary through time. However, one of them can always be regarded as the leading depositional process. Prevalence of karstic runoff is considered for the five sand layers, i.e. cluster 1 (Figs. 2, 4). As coarse-grained deposits they differ from the fine-grained silts related to seasonal flooding of the river. Therefore, they are regarded as short events and thus as stratigraphically insignificant. This is why these sand intercalations via karst hydrology are excluded from the discussion of past environmental conditions as well as from the selection of geochemical, elemental and sedimentological data plotted vs. time (Figs. 8-10). Based on these considerations, five different periods have been distinguished for this subtropical lake characterizing its Holocene environmental history.

\section{(1) Early Holocene $(10,400-7800$ cal. BP) - dominance of fluvial sedimentation: This period is} composed of LZs A1 and C and characterized by cluster 2 with increased values of Fe, $\mathrm{K}$ and Ti (Fig. 9) in a medium silt matrix. This type of sediment is introduced by suspension fallout during flooding of Rio Guabiroba. Moreover, the elemental composition excludes the Furnas Formation as the source for these deposits, because Fe and $\mathrm{K}$ are unknown from the sandstone of the Furnas Formation making river influence the only possible source. In terms of organic sediment components, the onset at 10,400 cal. BP reflects rather low values for TOC and BSi (Fig. 8). While TOC remains at such low levels throughout this period, diatom productivity (BSi) increases rapidly and reaches two distinct maxima at 8300 and 8000 cal. BP, both with microscopically detectable high numbers of planktonic diatoms. This increased diatom productivity might be fostered by relatively high amounts of $\mathrm{K}$ and $\mathrm{Si}$ together with other micronutrients essential for diatom growths introduced through fluvial discharge, while $\mathrm{N}$ remains rather low (Fig. 8) leaving non-siliceous algae at low numbers. In general, the lacustrine system of the Early Holocene is characterized by increasing nutrient levels, while the source of $\mathrm{OM}$ is dominantly lacustrine (C/N ratio: $10-15)$.

Rio Guabiroba flows on its flood plain with a very low gradient. This is indicated by the high degree of meandering along the river course (Fig. 1), which leads to the deposition of silt and sand in the river bed. During flooding, coarse silt and fine sand are deposited on the river banks forming a levee and finer grains cover the flood plain. Lagoa Dourada is situated on this flood plain and has a short-cut connecting river and lake. As flooding through this outflow channel occurs against the local gradient, flow velocity is expected to be low and only silt and clay can be transported and eventually deposited in the lake basin as suspension fallout. This process is supported by observations during coring, when low lake-water transparency due to high suspension loads occurred during a flood event changing to high lake-water transparency virtually hours after the flood event has ended. 
Another aspect to be mentioned is the availability of fine-grained material for river transport and deposition. Initially such material needs to be eroded, but erosion only occurs if the soil is not well protected by vegetation. Moreover, the type of rainfall increases the susceptibility to erosional processes: episodic precipitation during a drier climate results in higher erosion rates compared to more evenly distributed precipitation during a wetter climate. This would exclude forest as vegetation type for the Early Holocene as it protects from soil erosion. Thus, decreasing silt deposition during the subsequent early Middle Holocene transitional period is explained by woodland expansion as the consequence of higher rainfall reducing soil erosional processes. Another possible explanation could be that levees have been created in the course of several millennia protecting the flood plain more efficiently from flooding.

The final centuries of the Early Holocene (8300-7800 cal. BP) are characterized by an all-time maximum in planktonic diatom development (Fig. 8), a marked decrease in Ti as well as a distinct increase in K (Fig. 9). Together, this could be explained by increased precipitation, which would correspond to less soil erosion due to a denser vegetation cover (Ti), a higher degree of chemical weathering with related leaching of $\mathrm{K}$ and a deeper lake with more nutrients beneficial for planktonic diatom development (Fig. 9). This wetter period may represent the 8.2 ka event, which is characterized - according to model simulations - by more rainfall in S Brazil as a result of North Atlantic cooling and monsoon enhancement across Brazil (Morrill et al., 2013).

(2) Early Middle Holocene transition (7800-6200 cal. BP) - from dominance of fluvial influence to autochthonous lacustrine deposition: This combination of LZs A2 and D1 is a two-partite transitional period belonging to clusters 2 and 4 . On the one hand, BSi drops from 20 to $3 \%$ right at the beginning of this period and remains constantly low further on. On the other hand, TOC triples to values up to $15 \%$. This development goes along with an increase of the $\mathrm{C} / \mathrm{N}$ ratio from 12 to 30 , a change starting with a delay of 400 years, which indicates a higher influence of allochthonous OM interpreted as a decrease in water depth with less lacustrine and more catchment derived OM. This parallels an increase in mean grainsize from $20 \mu \mathrm{m}$ (middle silt) to $70 \mu \mathrm{m}$ (fine sand). $\mathrm{C} / \mathrm{N}$ and grainsize remain at their high levels until the end of the early Middle Holocene at $6200 \mathrm{cal}$. BP. A component related to OM that additionally comes into play during the latter part of this period is $S$ (Fig. 9). This element is low during the first part of this transition and increases markedly after 7400 cal. BP - a change that goes along with an increase in Fe. Formation of pyrite explains this process pointing to anoxic conditions at the lake floor and being responsible for the color change to darker hues with the onset of LZ D1. Finally, elements of the minerogenic sediment component relating to the river catchment area as source $(\mathrm{K}, \mathrm{Ti})$ loose importance towards the end of this transitional period (Fig. 9).

There are two possible options explaining the transition from silt-dominated sediments poor in OM to an increasing sand-dominance with more allochthonous OM. The general process behind this development is less influence of river flooding. Simultaneously, increasing influence of organic lacustrine productivity and/or runoff from the immediate catchment area of Lagoa Dourada with influx of allochthonous OM such as leaves and twigs is reflected by higher $\mathrm{C} / \mathrm{N}$ ratios. Buildup of levees preventing the floodplain from flooding could be regarded as an explanation. However, as the outflow channel from the lake always keeps an opening in the levee, this option seems unlikely. Instead, it is more likely that higher and more evenly distributed precipitation increased the density of vegetation, which on the one hand protects soils in the wider catchment area of Rio Guabiroba from erosion and thus reduces availability and river transport of fine-grained minerogenic matter. On the other hand, less suspension transport of the river frees fluvial energy increasing incision rates into the river bed and reducing the likelihood of flooding. As the second mechanism can be explained favorably by increased rainfall, we assume this process to be the most likely case explaining the change in depositional processes. 
More precipitation is also regarded as the reason for (1) higher activity of the karst hydrological system responsible for introducing sand into the lake; (2) intensified chemical weathering and thus increased pedogenesis in combination with denser vegetation making available more nutrients such as $\mathrm{N}$ and $\mathrm{P}$ (cf., Fig. 3 for $\mathrm{N}$ ). Additionally, the decrease in diatom abundance suggests other algae, such as blue-green algae (cyanobacteria), as being responsible for a fueled lacustrine productivity leading to anoxia at the lake bottom with formation of pyrite; and (3) an increased density of vegetation, which explains the higher contribution of allochthonous and lignin-rich OM responsible for increasing $\mathrm{C} / \mathrm{N}$ ratios (Fig. 8). The underlying change from a drier to a wetter landscape with adapting vegetation might be considered as the reason for this transition indicated by highest $\mathrm{C} / \mathrm{N}$ ratios and sand influx. It is interesting to note that this transitional period is framed by two (LZs B2 and E1) and includes a third (LZ B3) out of five sand horizons, which make up almost $87 \%$ of the thickness of all sand layers. This also confirms a higher activity of the karst hydrological system in the catchment area.

(3) Late Middle Holocene (6200-3800 cal. BP) - stabilization of lacustrine deposition: During the late Middle Holocene (LZ D2) the ecosystem stabilized with increasingly organic sediment deposition. Although BSi remains at its low level, TOC continues to rise to $20 \%$ until $4600 \mathrm{cal}$. BP, when a distinct drop to $10 \%$ occurs until 3800 cal. BP (Fig. 8). The only other parameter marking this change is grainsize, which coarsens towards a mean of $>100 \mu \mathrm{m}$. Thus, the drop in TOC likely is a result of dilution by additional quartz grains. However, the $\mathrm{C} / \mathrm{N}$ ratio is decreasing (Fig. 8), which excludes intensified surface runoff and suggests a stable catchment system with increased influx of sand via karstic springs. This is supported by continuing high levels of $S$ indicating anoxia as the result of increased organic lacustrine productivity probably dominated by blue-green algae.

Altogether, the lacustrine system further stabilized during this period as well as the catchment area, from where less terrestrial organic remains enter the lake and thus cause the $\mathrm{C} / \mathrm{N}$ ratio to decrease. However, between 4600 and 3800 cal. BP and thus prior to the onset of the Late Holocene, an increased activity of the karst hydrological system indicates wetter environmental conditions not only causing an increase in grain size but also the formation of the youngest sand layer (LZ E2) at this transitional period.

(4) Late Holocene (3800-150 cal. BP) - mature lacustrine deposition: The Late Holocene lake system matures in the course of LZ D3. OM steadily increases to a maximum of $>25 \%$ TOC and also BSi doubles to $5 \%$. At the same time, the $\mathrm{C} / \mathrm{N}$ ratio decreases indicating a more prominent contribution of autochthonous lacustrine OM. This is supported by $\mathrm{S}$ remaining at the same high level as during the Middle Holocene and thus documents the presence of anoxia at the lake bottom. Grainsize diminishes from a mean of 50 to $30 \mu \mathrm{m}$ as well as siliciclastic elements $(\mathrm{K}, \mathrm{Ti})$ decrease, indicating a minimum of minerogenic components. Altogether, the lake develops towards more eutrophic conditions with two TOC maxima at 1750 and 1000 cal. BP.

The ending of LZ D3 is characterized by distinctly dropping values for Ti and $\mathrm{K}$, which is best explained by denser vegetation inhibiting soil erosion. This interpretation argues in favor of higher precipitation as the responsible factor, i.e. a strengthening of the SAMS, comparable to the observation made for the 8.2 and 4.2 ka events. Due to more humid conditions with distinctly reduced export of erosionrelated elements $\mathrm{Ti}$ and $\mathrm{K}$ (lowest value of the entire record for $\mathrm{Ti}$ ), these four centuries are related to the LIA. However, the timing as determined by the radiocarbon-based age-depth model is $1000-$ 600 cal. BP (AD 950-1350; Fig. 10) and would be too old if compared to other available dates for the LIA in the Southern Hemisphere: 600-150 cal. BP or AD 1350-1800 (e.g., Bernal et al., 2016b). As the onset of the LIA is very distinct, we use this transition to adjust our chronology with the date of $A D$ 1350 for the beginning of the LIA (Fig. S6). The radiocarbon-based age-depth model (Fig. 7) provides an older age because the youngest ${ }^{14} \mathrm{C}$ age is $850 \mathrm{cal}$. BP (AD 1100). As the lithology is quite variable during the last millennium, a higher degree of variability has to be expected for the sedimentation rate, which is modelled as linear due to the lack of data points (Tab. 1, Fig. 7). 
(5) Human impact - returning dominance of fluvial sedimentation during the last two centuries: Drastic sedimentological changes occur after the preceding mature period within LZs F and G. Not only TOC, BSi, C/N ratio and grainsize decrease markedly in LZ F (Fig. 8), also all elemental data (Fig. 9) respond accordingly: $\mathrm{S}$ and $\mathrm{Si}$ drop to lower values while $\mathrm{Fe}, \mathrm{K}$ and Ti increase. $\mathrm{S}$ covaries with all organic productivity indicating proxies, which either points to a drop in organic productivity or to dilution by minerogenic matter. The latter seems to be the more likely explanation here because $\mathrm{Fe}$ is no longer correlating with $\mathrm{S}$ but with $\mathrm{K}$ and $\mathrm{Ti}$ instead. This indicates an increased presence of siliciclastic matter, which is supported by a change in color and higher $\mathrm{K}$ and Ti levels. The simultaneous drop in $\mathrm{Si}$ as well as the presence of Fe suggest that during this period the lake again received suspended sediment loads from Rio Guabiroba. The fine silt fraction observed has a mean grainsize of $6 \mu \mathrm{m}$ with highest contributions of clay (up to $33 \%$ ) and elevated Fe and K contents. These are not components of the Furnas sandstone but were produced by chemical weathering and pedogenesis of shales from the Ponta Grossa Formation.

668

669

670

671

672

673

674

675

676

677

678

679

680

681

682

683

684

685

686

687

688

689

690

691

692

693

694

695

696

697

698

699

700

701

If this sediment is the result of re-activated flooding of the river (cluster 3 of Fig. 4) then the question arises, which processes caused these deposits and shape them so markedly different from Early Holocene suspension load (cluster 2 of Fig. 4). The most convincing explanation includes human activity related to land-use change. Since the Middle Holocene, the vegetation became denser during wetter environmental conditions. These climatic conditions intensified chemical weathering and pedogenesis and thus altered the soils causing enrichment in $\mathrm{Fe}$, depletion in $\mathrm{K}$ and formation of the clay mineral kaolinite. These soils were stabilized by vegetation until European farmers claimed the land. While vegetation protects soils from erosion even under high rainfall conditions, land clearance immediately triggered erosional processes (cf., Zolitschka, 1998) often with the help of fire. As the soil-protecting canopy and stabilizing root systems were removed, less water is stored in vegetation and in soil OM increasing surface runoff and causing soil erosion. Relocated downslope, the river picks up the eroded material and transports it towards Lagoa Dourada. This high sediment freight of Rio Guabiroba gave rise to a high amount of deposition in the river bed, thus decreasing its cross section and the same time increasing the probability of flooding, which is regarded as the reason for deposition of LZ F.

However, this plausible interpretation of LZ F contradicts with the radiocarbon-based age-depth model suggesting 600 cal. BP (AD 1350) for the onset of human activities. This date opposes historical data of first European settlements in the region around Ponta Grossa at ca. AD 1800 (Freitas, 2011) with still marginal influences on the landscape, which was initially restricted to cattle breeding. Only decades later, land-use change accelerated around 1850 (Freitas, 2011). Altogether, this challenges the age-depth model for the last millennium with only one radiocarbon date at $850 \mathrm{cal}$. BP (Tab. 1, Fig. 7). We, therefore, add the historical date of AD 1800 (150 cal. BP) for the onset of agricultural activities in the hydrological catchment (Fig. S6).

Another explanation of clastic LZ F needs to be discussed assuming the age-depth model is correct (Fig. 7). For the time from 600-150 cal. BP (AD 1350-1800) natural climatic variability, such as the LIA, might be considered as a reason. Only few paleorecords provide evidences of the LIA for S Brazil. However, this is most likely a matter of temporal resolution being less adequate for detecting this rather short climatic fluctuation (cf., Bernal et al., 2016b). However, assuming the LIA as the reason for LZ F, causative processes are not supported by the sediment record of Lagoa Dourada. The impact of the LIA on climatic conditions for S Brazil is increased precipitation (Bernal et al., 2016b; Novello et al., 2021). Consequently, this is leading to denser vegetation with less soil erosion, a process described for the centuries immediately prior to LZ F. Thus, we refuse the option of considering the LIA as responsible for increased minerogenic deposition during LZ F and find further support for a necessary modification of our chronology for the last millennium (cf., Fig. S6).

This interpretation in combination with the modified age-depth model is supported by topmost lithozone (LZ G), which is characterized by a return to highly organic deposits (Fig. 8) around AD 1950 
(0 cal. BP). This corresponds to the establishment of the Vila Velha State Park in AD 1953. Thus, we can add another "historical" date to modify our chronology of the last millennium (Fig. S6). In combination with plantations of pine and eucalypt during the following decade, soil erosion was reduced. A return to highly organic sediments comparable to those prior to AD 800 was the result, except for two elements: N (Fig. 3) and K (Figs. 5, 9). Both elements increase considerably towards the top of the record, a process explained by the extensive use of fertilizers in the catchment area since the 1950ies.

(6) Refining the chronology: Altogether, we add three ages to our record to refine the radiocarbonbased chronology of the last millennium (Fig. S6):

- The onset of LZ G is linked to the establishment of the Vila Velha State Park in AD 1953 with a return to highly organic sediments caused by less soil erosion in the now (partly) protected catchment area in combination with intensified use of fertilizers causing eutrophication since the 1950ies (0 cal. BP);

- The onset of human influence with related agricultural activities and land-use changes causing high rates of soil erosion starting around AD $1800 \pm 50$ (150 \pm 50 cal. BP) and

0 The onset of the LIA with higher precipitation and denser vegetation leading to less leaching of elements like $\mathrm{K}$ and $\mathrm{Ti}$, which is anticipated for AD 1350 (600 cal. BP).

\section{Discussion}

Chronological considerations: Evidences in support of an Early Holocene basal age of the recovered sediments come from various sources. Although the oldest uncalibrated radiocarbon ages date the sediment core LD91 to 11,170 \pm 110 BP (Melo et al., 2003; Moro et al., 2004) and LD17-ID23 to 13,850 $\pm 70 \mathrm{BP}$ and $14,660 \pm 80 \mathrm{cal}$. BP (Tab. 1), these ages document influences of reservoir effects and are not providing a Lateglacial age for the basal sediments of Lagoa Dourada. This is confirmed by pollen and speleothem data. Palynological investigations at Serra dos Orgaos $\left(22.5^{\circ} \mathrm{S}\right)$ describe a warm and wet YD chronozone, which extends from 12,700-11,600 cal. BP (Behling and Safford, 2010). Similar climatic conditions are reconstructed with pollen from Serra do Tabuleiro at $28^{\circ} \mathrm{S}$ (Behling and Oliveira, 2017). Additionally, the reconstruction of precipitation using stable isotopes of a speleothem from Botuverá Cave at $27^{\circ} \mathrm{S}$ (Cruz et al., 2005) also characterizes the YD as wet comparable to the Late Holocene (Fig. 10A). There is no evidence for such a warm and wet period with forest expansion at the base of our record (Piraquive Bermúdez, 2020). Thus, we have further evidence that the obtained Lateglacial ages really are artefacts and the record from Lagoa Dourada starts with the Early Holocene.

Information about the age of the uppermost meter of sediment is deduced with links to the regional historic development. The pollen diagram of Cambara do Sul $\left(29^{\circ} \mathrm{S}\right)$ has a high sample resolution for the last centuries and indicates human activities. At this site European land use started after AD 1780 , first with cattle breeding followed by logging. Since AD 1820, settlements were established with accompanying agriculture (Behling et al., 2004). Furthermore, historic evidence for the introduction of neophytes (eucalypt and pine trees) to S Brazil dates back to AD 1904, when timber barons established first tests with these fast-growing tree species (Ayling and Martins, 1981). However, commercial eucalypt plantations near Lagoa Dourada did not occur before the mid-1960ies (Ayling and Martins, 1981). They are reported for Vila Velha State Park for AD 1964 (Government of the State of Paraná). Thus, we are confident that LZ G covers only the last $\sim 70$ years. The reason for the discrepancy between historical data and the radiocarbon-based age-depth model is the lack of ${ }^{14} \mathrm{C}$ ages for the last millennium, where distinct changes in sedimentation rate have implications for sedimentation rates (Fig. S6). 
Comparison with previously published data from Lagoa Dourada: Sediments from Lagoa Dourada (LD91) have been cored for the first time more than 30 years ago (Melo et al., 2003; Moro et al., 2004). However, this record is severely hampered by (1) very general sediment descriptions differing between Melo et al. (2003) and Moro et al. (2004); (2) many data are only available with low spatial resolution, i.e. one or two analyses per meter; and (3) the chronology is based on two radiocarbon dates only providing ages of $11,170 \pm 110 \mathrm{BP}$ and $8720 \pm 150 \mathrm{BP}$ from $11.9 \mathrm{~m}$ and $10.6 \mathrm{~m}$ of LD91, respectively. With these dates, a Lateglacial age has been proposed for the basal sediments at 12.2 $\mathrm{m}$. As a result of our study, these ages should be considered cautiously and not without considering a reservoir correction. Despite of these limitations, Melo et al. (2003) provide mineralogical data based on XRD analyses, which document the presence of quartz, kaolinite, illite, pyrite and gypsum. The latter is certainly an artefact and produced after core splitting when pyrite (FeS) oxidized and recrystallized as gypsum $\left(\mathrm{CaSO}_{4}\right)$. As total carbon percentages of this old record are erroneously low $(<0.83 \%)$, the presence of pyrite together with gypsum is interpreted as an indicator of dry (semiarid) climate conditions prior to $8720 \mathrm{BP}$ and as well for a period between 5000 and $3000 \mathrm{BP}$ (Melo et al., 2003). Furthermore, it is argued that the sand horizons are related to semi-arid conditions, when river runoff and thus flooding events did not occur while karstic springs provided water with quartz grains. While our study does not support these assumptions, the detection of a planktonic diatom maximum at $11.8 \mathrm{~m}$ by Moro et al. (2004) agrees with LZ C with its high BSi values and the microscopic detection of planktonic diatoms. Moreover, Moro et al. (2004) confirm the high concentration of $\mathrm{K}$ for a depth of $20 \mathrm{~cm}$, which they relate to NPK fertilizers applied in the catchment area, results that also agree with our study.

Comparison with pollen data from S and SE Brazil: Most paleoenvironmental data from S and SE Brazil is from palynological investigations. Here we compare our investigation with pollen records spanning a latitudinal range from 18 to $28^{\circ} \mathrm{S}$.

The pollen record from Serra do Tabuleiro $\left(28^{\circ} \mathrm{S}\right)$ provides a nicely dated and densely analyzed Early Holocene record (Behling and Oliveira, 2017). After the warm and wet second half of the YD, Campos vegetation (grassland) with a warm and dry climate dominated the Early Holocene until 8000 cal. BP. Compiling eleven pollen records covering the latitudes between 15 and $35^{\circ} \mathrm{S}$, Ledru et al. (1998) document warm and dry Early Holocene climatic conditions for the time period 11,400-7700 cal. BP. In a comparable synthesis, Behling (2002) uses 14 pollen records between 18 and $28^{\circ} \mathrm{S}$ and suggests $\sim 6300$ cal. BP as the end of warm and dry Early Holocene conditions. This data supports our interpretation of environmental conditions at Lagoa Dourada, where grassland vegetation under dry and warm climate conditions is proposed to explain erosion of fine-grained material in the catchment area via slope-wash (no or much less trees to protect against soil erosion), river transport and flooding until 7800 cal. BP (Fig. 8). This is also supported by data from NE Brazil, where the Middle Holocene shift from forest to grassland vegetation (Caatinga), i.e. from wet to dry conditions, caused an increase in soil-erosion rates due to less dense vegetation exposing soils to erosion during precipitation events (Jaqueto et al., 2016; Utida et al., 2020). In SE Brazil, this process not only caused intense colluvial deposition but also the formation of high fluvial terraces in the drainage systems of rivers dated to 11,400-9500 cal. BP (Suguio et al., 1989).

After a warm and dry onset of the Holocene, precipitation started to increase, causing a change from Campos vegetation to the development of forest at Serra do Tabuleiro (Behling and Oliveira, 2017). Increased moisture advection from the Amazon Basin with a weakening of polar advection results in an expansion of forests in S Brazil dated to $7700-4390$ cal. BP (Ledru et al., 1998). This process is not consistent in timing across S and SE Brazil (cf., Behling, 2002), a fact that may be due to the large latitudinal extension $(1300 \mathrm{~km})$ of available data, differences in elevation between coastal plains and the mountainous hinterland, chronological uncertainties and also to a time-transgressive spatial evolution or gradual shift of climatic conditions (Rodrigues et al., 2016). Higher rainfall with the expansion of forests is noted by other pollen records for a time period from 8900 until $5700 \mathrm{cal}$. BP (Behling, 1995, 2003; Behling and Oliveira, 2017; Behling and Safford, 2010; Enters et al., 2010; 
Rodrigues-Filho et al., 2002). This change from grassland to forest reduced hillslope denudation to a minimum and increased chemical weathering and pedogenesis with leaching of nutrients as documented by increased lacustrine productivity, e.g. at Lago Aleixo (Enters et al., 2010). This also transformed lacustrine sedimentological processes at Lagoa Dourada and at Lago Silvana at $19,5^{\circ} \mathrm{S}$ from silt-rich suspension fallout to Fe-rich organic sediments (Rodrigues-Filho et al., 2002).

Organic deposition continued until the last millennium when a few sites document a climatic fluctuation related to the LIA with warm and wetter climatic conditions. These have been detected for AD 1520-1780 at Cambara do Sul (Behling et al., 2004) and since AD 1390 at Lagoa Nova (Behling, 2003). For Lagoa Dourada less siliciclastic matter ( $\mathrm{K}$ and Ti; Fig. 9) is detected and possibly related to the LIA dated to AD 1350-1800 according to the modified chronology (Fig. S6).

Finally, human activities changed the ecosystems. Since the late $18^{\text {th }}$ century, European settlers started to use the area for farming (Behling and Oliveira, 2017; Portes et al., 2018). Agricultural activities (logging, cattle breeding, tillage) gave rise to increased soil erosion, as documented for Lagoa Dourada and less prominent for Lago Aleixo (Enters et al., 2010). In both cases, organic sediments were replaced by minerogenic sediments.

Comparison with other paleoclimate data: Speleothems currently provide the best dated climatic parameters for the reconstruction of precipitation in NE and SE Brazil (Baker and Fritz, 2015). In a distance of only $240 \mathrm{~km}$ SSE from Lagoa Dourada, speleothems from Caverna Botuverá $\left(27^{\circ} \mathrm{S}\right)$ provide high-resolution stable isotope data with a precise U/Th-based chronology dating back to 116 ka (Cruz et al., 2005). The obtained oxygen-isotope records (Fig. 10A, B) vary with the source of precipitation and thus are interpreted as proxies for atmospheric circulation and convective intensity, both closely related to the SAMS controlling hydroclimatic conditions. Summer convection over the Amazon Basin and associated monsoonal precipitation in S Brazil has a more negative oxygen isotope signature compared to winter rain related to incursions of mid-latitudinal storm tracks from the Atlantic Ocean (Cruz et al., 2005). These conditions are nicely summarized by Wang et al. (2007): "Low (high) Botuverá speleothem $\delta^{18} \mathrm{O}$ indicates intensified (weakened) SAMS activity, more (less) Amazon moisture contribution and higher (lower) rainfall in S Brazil." Thus, the isotopic record from Caverna Botuverá is linked to variability in precipitation caused by insolation-controlled fluctuations of the SAMS and provides one of the most robust climate reconstructions for South America. While the early studies of Caverna Botuverá focus on orbital to millennial timescales (Cruz et al., 2005; Wang et al., 2007), follow-up investigations obtained a much higher temporal resolution for the Holocene detecting decadal to centennial climatic variability (Bernal et al., 2016b; Novello et al., 2021), data which also are used for inter-hemispheric correlation of climate modes (Deininger et al., 2020). The high-resolution $\delta^{18} \mathrm{O}$ data are supported by even higher resolving trace-element data ( $\mathrm{Mg}, \mathrm{Ca}, \mathrm{Sr}, \mathrm{Ba})$. Especially the $\mathrm{Sr} / \mathrm{Ca}$ ratio correlates highly with $\delta^{18} \mathrm{O}$ (Fig. 10B, C) and is applied as a proxy that characterizes SAMS intensity and detects the effect of Holocene climate anomalies on regional hydroclimatic conditions while closely following summer insolation at $30^{\circ} \mathrm{S}$ (Bernal et al., 2016b). These data document a suppressed SAMS intensity during the Early Holocene and an increase starting around $7000 \mathrm{cal}$. BP. Due to the well-dated and high-resolution record, also centennial climatic events of the Holocene have been detected: the $8.2 \mathrm{ka}$ event and the LIA for the time interval AD 1400-1850 (Bernal et al., 2016b) - both characterized by wetter hydroclimatic conditions. A wet LIA (AD 1600-1850) with stronger SAMS is also documented by a compilation of speleothem $\delta^{13} \mathrm{C}$ data from 25 caves in tropical and subtropical South America (Novello et al., 2021).

In addition to the pronounced signals related to the $8.2 \mathrm{ka}$ event and to the LIA, another century-long climatic fluctuation is described for a sediment core from Lagoa Salgada ( $21^{\circ} \mathrm{S}$ and $\sim 1000 \mathrm{~km} \mathrm{NE}$ of Lagoa Dourada in Rio de Janeiro State) and linked to the 4.2 ka event (Soares Cruz et al., 2019). This climatic fluctuation is considered as a time of exceptional climatic anomalies worldwide, although its cause is still under discussion (Bradley and Bakke, 2019; Giesche et al., 2019; Kathayat et al., 2018; Scuderi et al., 2019). At Lagoa Salgada, a tripartite period of wetter climate conditions with a short 
central dry period is documented by geochemical, sedimentological and pollen investigations for the period 4200-3800 cal. BP (Soares Cruz et al., 2019). This climatic fluctuation corresponds to lower $\mathrm{Mg} / \mathrm{Ca}$ and $\mathrm{Sr} / \mathrm{Ca}$ ratios of the speleothem record from Caverna Botuverá supporting a generally wetter climate with a short central and dry period (Bernal et al., 2016b), while the high-resolution marine sediment record from Cariaco Basin (Venezuela) provides evidence for an overall drier climate with a short central wet section north of the equator (Hughen et al., 1996). The dry conditions at Cariaco Basin are considered to be the result of a southward shift of the ITCZ, which consequently can be regarded as the reason for wetter conditions in SE Brazil resulting from an intensification of the SAMS (Hughen et al., 1996; Soares Cruz et al., 2019).

All this hydroclimatic data agrees with our interpretation of the high-resolution record from Lagoa Dourada. The speleothem record underlines the observed environmental changes and provides the best possible precipitation signal solidifying the reconstructed surface processes that lead to the formation of the studied sediment sequence (Fig. 10D, E). The 8.2 ka event is characterized at Lagoa Dourada by increased BSi related to a maximum in planktonic diatom development (Fig. 8), a marked decrease in $\mathrm{Ti}$ and an increase in $\mathrm{K}$ (Figs. 9, 10D, E). These two centuries match with increased precipitation, which corresponds to less soil erosion due to denser vegetation (decrease in Ti), a higher degree of chemical weathering with related leaching of $K$ with not yet enough vegetation to retain all the released $\mathrm{K}$ in organic tissue (increase of $\mathrm{K}$ ) and a deeper lake with enough nutrients beneficial for the development of planktonic diatoms (Fig. 8). Despite of the diatom blooms, lacustrine productivity remains at a low level with overall minerogenic sediments being deposited.

The 4.2 ka event occurs at Lagoa Dourada from 4400-3800 cal. BP and in a tree-rich landscape with denser vegetation (Fig. 10). Thus, the increase in rainfall does not cause a decrease in soil erosion like during the 8.2 ka event as vegetation is already protecting the soils. Consequently, Ti shows no response to this event. The element $K$, however, has lower values because denser vegetation more efficiently inhibits $\mathrm{K}$ from being leached (Fig. 10). Less nutrient transfer from the catchment area to the lake might be one of the reasons for the contemporaneous drop in sediment organic matter at Lagoa Dourada (Fig. 8). Another explanation for this to occur is dilution by minerogenic matter, which is documented by a coarser mean grainsize (Fig. 8), possibly linked to intensification of the karst hydrological system during this wet period. Also, diatoms play no major role anymore. They are subordinated since the end of the $8.2 \mathrm{ka}$ event, when sediment composition switched from minerogenic to organogenic, probably due to generally higher influx of nutrients like $\mathrm{N}$ and $\mathrm{P}$ during the Middle and Late Holocene. Under such conditions, blue-green algae often outcompete diatoms, which explains why siliceous algae did not recover to the high values of the Early Holocene.

The responses of the lacustrine system of Lagoa Dourada to the climatic deterioration of the LIA is more or less comparable to the 4.2 ka event. However, on the one hand TOC decreases and mean grainsize increases only slightly, while on the other hand BSi has a minor maximum (Fig. 8).

Tentatively, this is interpreted as resulting from wetter conditions compared to the 4.2 ka event with distinctly denser vegetation, which reduces soil erosion (drop in $\mathrm{Ti}$ ) and leaching of nutrients (drop in $\mathrm{K}$ ) in the catchment area (Fig. 10). In consequence, this might have caused a less nutrient-rich lake leading to the observed increase in diatoms.

Comparison with archaeological data: Human population dynamics are in the focus of archaeological investigations of South America. Using radiocarbon dates of archaeological sites from the entire continent, a spatiotemporal pattern of human population growth has been reconstructed (Goldberg et al., 2016; Riris and Arroyo-Kalin, 2019). Aside from cultural and technological developments, climate change is considered as an additional factor modifying population dynamics. In this respect, it is interesting to note that one center of population growth is the area of the S Brazilian coast for the time interval $6000-4000$ cal. BP (Goldberg et al., 2016). This period corresponds to the late Middle Holocene stabilization period of the record from Lagoa Dourada (Fig. 8) with forests being well established providing stable food resources. In another study, climate is considered as a driver of 
cultural change and depopulation is attested for the Middle Holocene (8200-4200 cal. BP) with overall dominance of more arid climate conditions in South America (Riris and Arroyo-Kalin, 2019). However, their regionalization model provides a different picture for what is called the "Southern Cone", i.e. the subtropical and temperate southern part of the continent, with significantly higher population between 7500 and $4500 \mathrm{cal}$. BP compared to other regions of South America (Riris and Arroyo-Kalin, 2019). Again, this can be related to the stabilization period of the late Middle Holocene at Lagoa Dourada. Altogether, climate is not only the driver for biological and geomorphological systems but also responsible for demographic change of human populations. To better understand this complex system Earth, it is pertinent to provide more high-resolution and well-dated information for environmental reconstruction from natural archives with a larger regional coverage in South America.

\section{Conclusions}

Thirty years after first investigations of sediment from Lagoa Dourada (S Brazil), our re-visit of this site provides a wealth of information shedding new light on environmental responses triggered by dominating climatic control mechanisms, which are related to intensity variations of the South American Monsoon System (SAMS). We recovered two overlapping sediment profiles with a basal depth of $14.4 \mathrm{mcd}$. Time control is obtained by applying sophisticated age-depth modelling after combining AMS radiocarbon dates on terrestrial macrofossils with reservoir-corrected ages of bulk organic matter. Based on this chronology, XRF core-scanning data together with geochemical and sedimentological studies provide high-resolution insights into responses of lacustrine and geomorphological systems to climatic variability and anthropogenic impacts. Altogether, the sediment record of Lagoa Dourada constitutes a powerful tool for investigating a detailed regional hydroclimatic history of the Holocene with unequivocal linkages to other regional and highresolution studies, namely the speleothem records from Caverna Botuverá (Bernal et al., 2016b; Novello et al., 2021).

Based on statistical analyses of the high-resolution dataset from Lagoa Dourada, four different sediment sources were characterized geochemically and relate to lacustrine organic productivity, underground karst runoff, river flooding and cultural soil erosion. Thus, our comprehensive and welldated multiproxy dataset provides a handle on process-related developments in the lake and its catchment area and allows insights into physical landscape changes as well as into geomorphological and lacustrine processes - all reflecting environmental responses to hydroclimatic variability during the Holocene and to human activities during the last two centuries. As such, this new record from Lagoa Dourada fills a knowledge gap with regard to hydroclimatic variability and its impact on environmental systems for S Brazil and beyond. Moreover, these sediments provide an essential contribution to understand how precipitation changes influenced the resilience of ecosystems and their responses to global climate change, which is important background information to better constrain model projections of future precipitation and their impacts on environmental change.

Our high-resolution data documents dominating flooding through Rio Guabiroba with suspension fallout of minerogenic particles transferred to the lake via fluvial activity during the Early Holocene. Between 7800 and 6200 cal. BP, a transition to highly organic lacustrine deposits is observed, when fluvial influences were replaced by increasingly organic lacustrine deposition. This is due to decreasing availability of minerogenic particles from hillslope denudation and river transport as a result of intensified pedogenesis under developing forests. Furthermore, this transition period is characterized by sand horizons, which link to more runoff through the karst hydrological system -a process less well understood but also linked to increased precipitation. Once established, autochthonous lacustrine processes dominate sediment formation for the remaining Holocene, except for the topmost centuries. Based on a modified chronology for the last millennium, European 
settlers caused severe soil erosion as a result of land-use change between AD 1800 and 1950. For the youngest ca. 70 years, organic deposition reconvenes with evidences of increased eutrophication documented by high values for nitrogen and potassium acting as nutrients for lake biota.

The climatic development from a warm and dry Early Holocene to a warm and wet Middle and Late Holocene is in response to a strengthening of the SAMS. In addition to this general trend, the sediment record from Lagoa Dourada documents three of the two most prominent Holocene climatic events: the 8.2 ka event, the 4.2 ka event and the Little Ice Age. For Lagoa Dourada, these reflect several century-long increases in rainfall with complex responses of the environmental system -a result that favorably agrees with the climatic signal preserved by the speleothem record from Caverna Botuverá (Bernal et al., 2016b).

Future tasks to exploit this sediment record even further will link sedimentological and geochemical results with paleobiological data (Piraquive Bermúdez, 2020) to improve our understanding of interactions between regional vegetation and the geomorphological system in response to climate change. Remaining is the challenge of coring a longer sediment record from Lagoa Dourada with the ultimate goal to penetrate into the Pleistocene and to discover imprints of environmental changes linked to the Younger Dryas and the Antarctic Cold Reversal.

\section{Data Availability}

The multiproxy dataset of the lacustrine sediment record from Lagoa Dourada is accessible via the PANGAEA data archiving and publication system at https://doi.pangaea.de/10.1594/PANGAEA.xxxxxx. [The correct link will be provided during revisions.]

\section{Supplemental Material}

Supplementary figures and tables to this article are available online.

\section{Acknowledgements}

We are grateful to Vivian Luciana Jeske-Pieruschka (Universidade Federal do Ceará, Fortaleza, Brazil) for assistance in the field and organizing permits for the Vila Velha State Park. Support for sample preparation and analyses in the GEOPOLAR lab (University of Bremen) was provided by Carsten Smidt, Sabine Stahl and Rafael Stiens. Thanks also go to Hermann Behling (University of Göttingen) for support with field work and for critical comments on the draft as well as to Lujan Garcia (University of Bremen) for improving an earlier version of the manuscript. Finally, we acknowledge the constructive comments contributed by two anonymous reviewers. This research was funded by the Deutsche Forschungsgemeinschaft (DFG, German Research Foundation) as project GI 732/8-1.

\section{References}

Abdi, H., Williams, L.J., 2010. Principal Component Analysis. John Wiley \& Sons, Ltd. . http://dx.doi.org/https://doi.org/10.1002/wics.101

Aitchison, J., 1982. The statistical analysis of compositional data. Journal of the Royal Statistical Society. Series B: Statistical Methodology 44, 139-177. 
Ayling, R.D., Martins, P.J., 1981. The growing of eucalypts on short rotation in Brazil. The Forestry Chronicle February 1981, 9-16.

Baker, P.A., Fritz, S.C., 2015. Nature and causes of Quaternary climate variation of tropical South America. Quaternary Sci Rev 124, 31-47. http://dx.doi.org/10.1016/j.quascirev.2015.06.011

Behling, H., 1995. A high resolution Holocene pollen record from Lago do Pires, SE Brazil: vegetation, climate and fire history. Journal of Paleolimnology 14, 253-268.

Behling, H., 2002. South and southeast Brazilian grasslands during Late Quaternary times: a synthesis. Palaeogeogr Palaeocl 177, 19-27. http://dx.doi.org/Doi 10.1016/S0031-0182(01)00349-2

Behling, H., 2003. Late glacial and Holocene vegetation, climate and fire history inferred from Lagoa Nova in the southeastern Brazilian lowland. Vegetation History and Archaeobotany 12, 263-270. http://dx.doi.org/10.1007/s00334-003-0020-9

Behling, H., Oliveira, M.A.T.d., 2017. Evidence of a late glacial warming event and early Holocene cooling in the southern Brazilian coastal highlands. Quaternary Research 89, 90-102. http://dx.doi.org/10.1017/qua.2017.87

Behling, H., Pillar, V.D., Orlóci, L., Bauermann, S.G., 2004. Late Quaternary Araucaria forest, grassland (Campos), fire and climate dynamics, studied by high-resolution pollen, charcoal and multivariate analysis of the Cambará do Sul core in southern Brazil. Palaeogeography, Palaeoclimatology, Palaeoecology 203, 277-297. http://dx.doi.org/10.1016/s00310182(03)00687-4

Behling, H., Safford, H.D., 2009. Late-glacial and Holocene vegetation, climate and fire dynamics in the Serra dos Órgãos, Rio de Janeiro State, southeastern Brazil. Global Change Biology 16, 16611671. http://dx.doi.org/10.1111/j.1365-2486.2009.02029.x

Behling, H., Safford, H.D., 2010. Late-glacial and Holocene vegetation, climate and fire dynamics in the Serra dos Órgãos, Rio de Janeiro State, southeastern Brazil. Global Change Biology 16, 16611671. http://dx.doi.org/10.1111/j.1365-2486.2009.02029.x

Bernal, J.P., Cruz, F.W., Strikis, N.M., Wang, X., Deininger, M., Catunda, M.C.A., Ortega-Obregón, C., Cheng, H., Edwards, R.L., Auler, A.S., 2016a. Botuverá Cave, Brazil - High-resolution Trace Metal and Stable Isotope Speleothem Data covering the last 10,000 Years, 21.12.2016 ed. https://www.ncdc.noaa.gov/paleo/study/21060

Bernal, J.P., Cruz, F.W., Stríkis, N.M., Wang, X., Deininger, M., Catunda, M.C.A., Ortega-Obregón, C., Cheng, H., Edwards, R.L., Auler, A.S., 2016b. High-resolution Holocene South American monsoon history recorded by a speleothem from Botuverá Cave, Brazil. Earth and Planetary Science Letters 450, 186-196. http://dx.doi.org/10.1016/j.epsl.2016.06.008

Blaauw, M., Christen, J.A., Aquino Lopez, M.A., 2021. rbacon: Age-Depth Modelling using Bayesian Statistics, $R$ package version 2.5.1. ed.

Blott, S.J., Pye, K., 2001. GRADISTAT: a grain size distribution and statistics package for the analysis of unconsolidated sediments. Earth Surface Processes and Landforms 26, 1237-1248. http://dx.doi.org/10.1002/esp.261

Bradley, R.S., Bakke, J., 2019. Is there evidence for a 4.2 ka BP event in the northern North Atlantic region? Clim Past 15, 1665-1676. http://dx.doi.org/10.5194/cp-15-1665-2019

Bronk Ramsey, C., 2009. Bayesian analysis of radiocarbon dates. Radiocarbon 51, 337-360.

Carnaval, A.C., Hickerson, M.J., Haddad, C.F.B., Rodrigues, M.T., Moritz, C., 2009. Stability Predicts Genetic Diversity in the Brazilian Atlantic Forest Hotspot. Science 323, 785-789. http://dx.doi.org/10.1126/science.1166955

Croudace, I.W., Löwemark, L., Tjallingii, R., Zolitschka, B., 2019. Current perspectives on the capabilities of high resolution XRF core scanners. Quatern Int 514, 5-15. http://dx.doi.org/10.1016/i.quaint.2019.04.002

Croudace, I.W., Rindby, A., Rothwell, R.G., 2006. ITRAX: description and evaluation of a new multifunction X-ray core scanner, in: Rothwell, R.G. (Ed.), New techniques in sediment core analysis. The Geological Society of London Special Publications, London, pp. 51-63.

Croudace, I.W., Rothwell, R.G., 2015. Future Developments and Innovations in High-Resolution Core Scanning. Dev Paleoenviron Res 17, 627-647. http://dx.doi.org/10.1007/978-94-017-9849-5 27 
Cruz, F.W., Burns, S.J., Jercinovic, M., Karmann, I., Sharp, W.D., Vuille, M., 2007. Evidence of rainfall variations in Southern Brazil from trace element ratios $(\mathrm{Mg} / \mathrm{Ca}$ and $\mathrm{Sr} / \mathrm{Ca})$ in a Late Pleistocene stalagmite. Geochimica et Cosmochimica Acta 71, 2250-2263.

http://dx.doi.org/10.1016/i.gca.2007.02.005

Cruz, F.W., Burns, S.J., Karmann, I., Sharp, W.D., Vuille, M., Cardoso, A.O., Ferrari, J.A., Silva Dias, P.L., Viana Jr, O., 2005. Insolation-driven changes in atmospheric circulation over the past 116,000 years in subtropical Brazil. Nature 434, 63-66. http://dx.doi.org/10.1029/

Cruz, F.W., et al., 2005. Botuverá Cave, Brazil Stalagmite Stable Isotope Data, 03/2005 ed. IGBP PAGES/World Data Center for Paleoclimatology, Data Contribution Series \# 2005-027, NOAA/NCDC Paleoclimatology Program, Boulder CO, USA.

Cruz, F.W., Vuille, M., Burns, S.J., Wang, X., Cheng, H., Werner, M., Lawrence Edwards, R., Karmann, I., Auler, A.S., Nguyen, H., 2009. Orbitally driven east-west antiphasing of South American precipitation. Nat Geosci 2, 210-214. http://dx.doi.org/10.1038/ngeo444

Dean, W.E., 1974. Determination of Carbonate and Organic-Matter in Calcareous Sediments and Sedimentary-Rocks by Loss on Ignition - Comparison with Other Methods. Journal of Sedimentary Petrology 44, 242-248.

Dearing, J., 1994. Environmental magnetic susceptibility: using the Bartington MS2 system. Chi Publishing, Keniloworth.

Deininger, M., McDermott, F., Cruz, F.W., Bernal, J.P., Mudelsee, M., Vonhof, H., Millo, C., Spotl, C., Treble, P.C., Pickering, R., Scholz, D., 2020. Inter-hemispheric synchroneity of Holocene precipitation anomalies controlled by Earth's latitudinal insolation gradients. Nat Commun 11, 5447. http://dx.doi.org/10.1038/s41467-020-19021-3

Deininger, M., Ward, B.M., Novello, V.F., Cruz, F.W., 2019. Late Quaternary Variations in the South American Monsoon System as Inferred by Speleothems-New Perspectives using the SISAL Database. Quaternary 2. http://dx.doi.org/10.3390/quat2010006

Enters, D., Behling, H., Mayr, C., Dupont, L., Zolitschka, B., 2010. Holocene environmental dynamics of south-eastern Brazil recorded in laminated sediments of Lago Aleixo. Journal of Paleolimnology 44, 265-277. http://dx.doi.org/10.1007/s10933-009-9402-z

Folk, R.L., Ward, W.C., 1957. Brazos river bar: a study in the significance of grain size parameters. Journal of Sedimentary Petrology 27, 3-26.

Freitas, F., 2011. Land Use and Deforestation in Southeastern Brazil - 1753-1840, pp. https://fredericofreitas.org/2011/2011/2018/land-use-and-deforestation-in-southeastern-brazil1753-1840/\#f2011.

Giesche, A., Staubwasser, M., Petrie, C.A., Hodell, D.A., 2019. Indian winter and summer monsoon strength over the $4.2 \mathrm{ka}$ BP event in foraminifer isotope records from the Indus River delta in the Arabian Sea. Clim Past 15, 73-90. http://dx.doi.org/10.5194/cp-15-73-2019

Goberno do Estado de Paraná, 2004. Plano de Manejo Parque Estadual de Vila Velha.

Goldberg, A., Mychajliw, A.M., Hadly, E.A., 2016. Post-invasion demography of prehistoric humans in South America. Nature 532, 232-235. http://dx.doi.org/10.1038/nature17176

Harris, C.R., Millman, K.J., van der Walt, S.J., Gommers, R., Virtanen, P., Cournapeau, D., Wieser, E., Taylor, J., Berg, S., Smith, N.J., Kern, R., Picus, M., Hoyer, S., van Kerkwijk, M.H., Brett, M., Haldane, A., del Río, J.F., Wiebe, M., Peterson, P., Gérard-Marchant, P., Sheppard, K., Reddy, T., Weckesser, W., Abbasi, H., Gohlke, C., Oliphant, T.E., 2020. Array programming with NumPy. Nature 585, 357-362. http://dx.doi.org/10.1038/s41586-020-2649-2

Hogg, A., Heaton, T., Hua, Q., Palmer, J., Turney, C., Southon, J., Bayliss, A., Blackwe Boswijk, G., Bronk Ramsey, C., Pearson, C., Petchey, F., Reimer, P., Reimer, R., Wacker, L., 2020. SHCal20 Southern Hemisphere calibration, 0-55,000 years cal BP. Radiocarbon 62. http://dx.doi.org/doi: 10.1017/RDC.2020.59

Hughen, K.A., Overpeck, J.T., Peterson, L.C., Trumbore, S., 1996. Rapid climate changes in the tropical Atlantic region during the last deglaciation. Nature 380, 51-54. http://dx.doi.org/10.1038/380051a0 
Hunter, J.D., 2007. Matplotlib: A 2D Graphics Environment. Computing in Science and Engineering 9, 99-104.

Jaqueto, P., Trindade, R.I.F., Hartmann, G.A., Novello, V.F., Cruz, F.W., Karmann, I., Strauss, B.E., Feinberg, J.M., 2016. Linking speleothem and soil magnetism in the Pau d'Alho cave (central South America). Journal of Geophysical Research: Solid Earth 121. http://dx.doi.org/doi:10.1002/2016JB013541

Jeske-Pieruschka, V., Pillar, V.D., De Oliveira, M.A.T., Behling, H., 2013. New insights into vegetation, climate and fire history of southern Brazil revealed by a 40,000 year environmental record from the State Park Serra do Tabuleiro. Vegetation History and Archaeobotany 22, $299-314$. http://dx.doi.org/10.1007/s00334-012-0382-y

Kathayat, G., Cheng, H., Sinha, A., Berkelhammer, M., Zhang, H., Duan, P., Li, H., Li, X., Ning, Y., Edwards, R.L., 2018. Evaluating the timing and structure of the $4.2 \mathrm{ka}$ event in the Indian summer monsoon domain from an annually resolved speleothem record from Northeast India. Clim Past 14, 1869-1879. http://dx.doi.org/10.5194/cp-14-1869-2018

Ledru, M.-P., Mourguiart, P., Riccomini, C., 2009. Related changes in biodiversity, insolation and climate in the Atlantic rainforest since the last interglacial. Palaeogeography, Palaeoclimatology, Palaeoecology 271, 140-152. http://dx.doi.org/10.1016/j.palaeo.2008.10.008

Ledru, M.-P., Salgado-Labouriau, M.L., Lorscheitter, M.L., 1998. Vegetation dynamics in southern and central Brazil during the last 10,000 yr B.P. Review of Palaeobotany and Palynology 99, 131-142.

Liu, X., Colman, S.M., Brown, E.T., Minor, E.C., Li, H., 2013. Estimation of carbonate, total organic carbon, and biogenic silica content by FTIR and XRF techniques in lacustrine sediments. Journal of Paleolimnology 50, 387-398. http://dx.doi.org/10.1007/s10933-013-9733-7

Lorscheitter, M.L., Takeda, I.J.M., 1995. Reconstituição paleoambiental da região dos Campos Gerais, Paraná, através da palinologia de sedimentos da Lagoa Dourada, V Congresso da Associação Brasileira de Estudos do Quaternário, XI Simpósio de Sedimentologia Costeira, . Anais. Niterói, ABEQUA, 18-21, Niterói, RJ, pp. 18-21.

Löwemark, L., Bloemsma, M., Croudace, I., Daly, J.S., Edwards, R.J., Francus, P., Galloway, J.M., Gregory, B.R.B., Steven Huang, J.-J., Jones, A.F., Kylander, M., Löwemark, L., Luo, Y., Maclachlan, S., Ohlendorf, C., Patterson, R.T., Pearce, C., Profe, J., Reinhardt, E.G., Stranne, C., Tjallingii, R., Turner, J.N., 2019. Practical guidelines and recent advances in the Itrax XRF core-scanning procedure. Quatern Int 514, 16-29. http://dx.doi.org/10.1016/i.quaint.2018.10.044

Martin-Puertas, C., Tjallingii, R., Bloemsma, M., Brauer, A., 2017. Varved sediment responses to early Holocene climate and environmental changes in Lake Meerfelder Maar (Germany) obtained from multivariate analyses of micro X-ray fluorescence core scanning data. Journal of Quaternary Science 32, 427-436. http://dx.doi.org/10.1002/jqs.2935

McInnes, L., Healy, J., Astels, S., 2017. Hdbscan: Hierarchical Density Based Clustering. The Journal of Open Source Software 2, 205.

http://dx.doi.org/http://joss.theoj.org/papers/10.21105/joss.00205

Melo, M.S., Giannini, P.C.F., Pessenda, L.C.R., Neto Brandt, M., 2003. Holocene paleoclimatic reconstruction based on the Lagoa Dourada deposits, southern Brazil. Geologica Acta: an international Earth science journal 1, 289-302.

Melo, M.S.d., Coimbra, A.M., 1996. Ruiniform relief in sandstones: the example of Vila Velha, Carboniferous of the Parana Basin, Southern Brazil. Acta Geologica Hispanica 31, 25-40.

Melo, M.S.d., Giannini, P.C.F., 2007. Sandstone dissolution landforms in the Furnas Formation, southern Brazil. Earth Surface Processes and Landforms 32, 2149-2164. http://dx.doi.org/10.1002/esp.1520

Merkel, A., 2020. Climate data of Ponta Grossa, Brasil www.climatedata.org/suedamerika/brasilien/parana/ponta-grossa-4493/.

Meyers, P.A., Teranes, J.L., 2001. Sediment Organic Matter, in: Last, W.M., Smol, J.P. (Eds.), Tracking Environmental Change Using Lake Sediments. Volume 2: Physical and Geochemical Methods. Kluwer Academic Publishers, Dordrecht, pp. 239-269. 
Moro, R.S., de Mattos Bicudo, C.E., de Melo, M.S., Schmitt, J., 2004. Paleoclimate of the late Pleistocene and Holocene at Lagoa Dourada, Paraná State, southern Brazil. Quatern Int 114, 87 99. http://dx.doi.org/10.1016/s1040-6182(03)00044-2

Moro, R.S., Fürstenberger, C.B., 1998. Inferring lakewater characteristics in Lagoa Dourada, PR, Brazil, from surface sediment diatom assemblage data. Internationale Vereinigung für theoretische und angewandte Limnologie: Verhandlungen 26, 1755-1757. http://dx.doi.org/10.1080/03680770.1995.11901037

Morrill, C., LeGrande, A.N., Renssen, H., Bakker, P., Otto-Bliesner, B.L., 2013. Model sensitivity to North Atlantic freshwater forcing at $8.2 \mathrm{ka}$. Clim Past 9, 955-968.

Müller, P.J., Schneider, R., 1993. An automated leaching method for the determination of opal in sediments and particulate matter. Deep Sea Research Part I: Oceanographic Research Papers 40, 425-444.

Myers, N., Mittermeier, R.A., Mittermeier, C.G., Fonseca, G.A.B.d., Kent, J., 2000. Biodiversity hotspots for conservation priorities. Nature $403,853-858$.

Nesje, A., Søgnen, K., Elgersma, A., Dahl, S.O., 1987. A Piston Corer for Lake Sediments. Norsk Geografisk Tidsskrift - Norwegian Journal of Geography 41, 123-125. http://dx.doi.org/https://doi.org/10.1080/00291958708621986

Novello, V.F., Cruz, F.W., Vuille, M., Strikis, N.M., Edwards, R.L., Cheng, H., Emerick, S., de Paula, M.S., Li, X., Barreto, E.S., Karmann, I., Santos, R.V., 2017. A high-resolution history of the South American Monsoon from Last Glacial Maximum to the Holocene. Sci Rep 7, 44267. http://dx.doi.org/10.1038/srep44267

Novello, V.F., William da Cruz, F., Vuille, M., Pereira Silveira Campos, J.L., Stríkis, N.M., Apaéstegui, J., Moquet, J.S., Azevedo, V., Ampuero, A., Utida, G., Wang, X., Paula-Santos, G.M., Jaqueto, P., Ruiz Pessenda, L.C., Breecker, D.O., Karmann, I., 2021. Investigating $\delta 13 C$ values in stalagmites from tropical South America for the last two millennia. Quaternary Sci Rev 255. http://dx.doi.org/10.1016/j.quascirev.2021.106822

Nowaczyk, N.R., 2001. Logging of magnetic susceptibility, in: Last, W.M., Smol, J.P. (Eds.), Tracking environmental changes using lake sediments. Volume 1: Basin analysis, coring, and chronological techniques. Kluwer Academic Publishers, Dordrecht, The Netherlands, pp. 155-170.

Pedregosa, F., Varoquaux, G., Gramfort, A., Michel, V., Thirion, B., Grisel, O., Blondel, M., 2011. ScikitLearn: Machine Learning in Python. Journal of Machine Learning Research 12, 2825-2830.

Piraquive Bermúdez, D., 2020. Vegetation and fire history in Araucaria forest and grasslands, southern Brazil, Doctoral Thesis, University of Göttingen,144.

Piraquive Bermúdez, D., Theuerkauf, M., Giesecke, T., 2021. Towards quantifying changes in forest cover in the Araucaria forest-grassland mosaic in southern Brazil. Vegetation History and Archaeobotany. http://dx.doi.org/https://doi.org/10.1007/s00334-021-00841-2

Pires, L.F., Melo, M.S.d., Borges, J.A.R., Heck, R.J., Facin, P.C., 2019. X-ray Microtomography to Quantify Morphological Sandstones Properties. Brazilian Archives of Biology and Technology 62, e19180125. http://dx.doi.org/10.1590/1678-4324-2019180125

Pontes, H., Fernandes, L., de Melo, M., Guimarães, G., Massuqueto, L., 2020. Speleothems in quartzsandstone caves of Ponta Grossa municipality, Campos Gerais region, Paraná state, southern Brazil. International Journal of Speleology 49, 119-136. http://dx.doi.org/10.5038/1827806x.49.2.2313

Portes, M.C.G.d.O., Safford, H., Behling, H., 2018. Humans and climate as designers of the landscape in Serra da Bocaina National Park, southeastern Brazil, over the last seven centuries. Anthropocene 24, 61-71. http://dx.doi.org/10.1016/i.ancene.2018.11.004

Riris, P., Arroyo-Kalin, M., 2019. Widespread population decline in South America correlates with mid-Holocene climate change. Sci Rep 9, 6850. http://dx.doi.org/10.1038/s41598-019-43086-w

Rodrigues-Filho, S., Behling, H., Irion, G., Müller, G., 2002. Evidence for Lake Formation as a Response to an Inferred Holocene Climatic Transition in Brazil. Quaternary Research 57, 131-137. http://dx.doi.org/10.1006/qres.2001.2281 
Rodrigues, J.M., Behling, H., Giesecke, T., 2016. Holocene dynamics of vegetation change in southern and southeastern Brazil is consistent with climate forcing. Quaternary Sci Rev 146, 54-65. http://dx.doi.org/10.1016/i.quascirev.2016.06.011

Rothwell, R.G., 1989. The Smear Slide Method - An Optical Identification Guide. Springer, Dordrecht. http://dx.doi.org/https://doi.org/10.1007/978-94-009-1133-8 2

Scuderi, L.A., Yang, X., Ascoli, S.E., Li, H., 2019. The 4.2 ka BP Event in northeastern China: a geospatial perspective. Clim Past 15, 367-375. http://dx.doi.org/10.5194/cp-15-367-2019

Soares Cruz, A.P., Fernandes Barbosa, C., Blanco, A.M., de Oliveira, C.A., Guizan Silva, C., Sícoli Seoane, J.C., 2019. Mid-late Holocene event registered in organo-siliciclastic sediments of Lagoa Salgada carbonate system, southeast Brazil. Clim Past 15, 1363-1373. http://dx.doi.org/10.5194/cp-15-1363-2019

Suguio, K., Turcq, B., Servant, M., Soubiös, F., Foumier, M., 1989. Holocene fluvial deposits in southeastem Brazil: chronology and palaeohydrological implications, International Symposium on Global Changes in South America During the Quatemary, 7G-73, Säo Paulo (Brazil), pp. 70-74.

Thomaz, G.M., 2010. Vila Velha State Park, Brazil: Curious and Very Interesting Sandstone Formations, pp. https://traveltoparana.wordpress.com/2010/2005/2006/parque-estadual-devila-velha-state-park-parana-brazil/.

Tjallingii, R., Röhl, U., Kölling, M., Bickert, T., 2007. Influence of the water content on X-ray fluorescence core-scanning measurements in soft marine sediments. Geochemistry, Geophysics, Geosystems 8, 1-12. http://dx.doi.org/doi:10.1029/2006GC001393

Utida, G., Cruz, F.W., Santos, R.V., Sawakuchi, A.O., Wang, H., Pessenda, L.C.R., Novello, V.F., Vuille, M., Strauss, A.M., Borella, A.C., Stríkis, N.M., Guedes, C.C.F., Dias De Andrade, F.R., Zhang, H., Cheng, H., Edwards, R.L., 2020. Climate changes in Northeastern Brazil from deglacial to Meghalayan periods and related environmental impacts. Quaternary Sci Rev 250, 106655. http://dx.doi.org/10.1016/i.quascirev.2020.106655

van der Walt, S., Schönberger, J., Nunez-Iglesias, J., Boulogne, F., Warner, J., Yager, N., Gouillart, E., $\mathrm{Yu}, \mathrm{T}$., the scikit-image contributors, 2014. scikit-image: image processing in Python. PeerJ 2, e453. http://dx.doi.org/https://doi.org/10.7717/peerj.453

Virtanen, P., Gommers, R., Oliphant, T.E., Haberland, M., Reddy, T., Cournapeau, D., Burovski, E., Peterson, P., Weckesser, W., Bright, J., van der Walt, S.J., Brett, M., Wilson, J., Millman, K.J., Mayorov, N., Nelson, A.R.J., Jones, E., Kern, R., Larson, E., Carey, C.J., Polat, I.., Feng, Y., Moore, E.W., VanderPlas, J., Laxalde, D., Perktold, J., Cimrman, R., Henriksen, I., Quintero, E.A., Harris, C.R., Archibald, A.M., Ribeiro, A.H., Pedregosa, F., van Mulbregt, P., Vijaykumar, A., Bardelli, A.P., Rothberg, A., Hilboll, A., Kloeckner, A., Scopatz, A., Lee, A., Rokem, A., Woods, C.N., Fulton, C., Masson, C., Häggström, C., Fitzgerald, C., Nicholson, D.A., Hagen, D.R., Pasechnik, D.V., Olivetti, E., Martin, E., Wieser, E., Silva, F., Lenders, F., Wilhelm, F., Young, G., Price, G.A., Ingold, G.-L., Allen, G.E., Lee, G.R., Audren, H., Probst, I., Dietrich, J.P., Silterra, J., Webber, J.T., Slavič, J., Nothman, J., Buchner, J., Kulick, J., Schönberger, J.L., de Miranda Cardoso, J.V., Reimer, J., Harrington, J., Rodríguez, J.L.C., Nunez-Iglesias, J., Kuczynski, J., Tritz, K., Thoma, M., Newville, M., Kümmerer, M., Bolingbroke, M., Tartre, M., Pak, M., Smith, N.J., Nowaczyk, N., Shebanov, N., Pavlyk, O., Brodtkorb, P.A., Lee, P., McGibbon, R.T., Feldbauer, R., Lewis, S., Tygier, S., Sievert, S., Vigna, S., Peterson, S., More, S., Pudlik, T., Oshima, T., Pingel, T.J., Robitaille, T.P., Spura, T., Jones, T.R., Cera, T., Leslie, T., Zito, T., Krauss, T., Upadhyay, U., Halchenko, Y.O., Vázquez-Baeza, Y., SciPy, C., 2020. SciPy 1.0: fundamental algorithms for scientific computing in Python. Nature Methods 17, 261-272. http://dx.doi.org/10.1038/s41592-019-0686-2

Wang, X., Auler, A.S., Edwards, R.L., Cheng, H., Ito, E., Wang, Y., Kong, X., Solheid, M., 2007. Millennial-scale precipitation changes in southern Brazil over the past 90,000 years. Geophys Res Lett 34, n/a-n/a. http://dx.doi.org/10.1029/2007gl031149

Weltje, G., Bloemsma, M., Tjallingii, R., Heslop, D., Röhl, U., Croudace, I., 2015. Prediction of Geochemical Composition from XRF Core Scanner Data: A New Multivariate Approach Including Automatic Selection of Calibration Samples and Quantification of Uncertainties, in: Croudace, I., 
Rothwell, R. (Eds.), Micro-XRF Studies of Sediment Cores. Springer, Dordrecht, pp. 507-534. http://dx.doi.org/https://doi.org/10.1007/978-94-017-9849-5 21

Weltje, G.J., Tjallingii, R., 2008. Calibration of XRF core scanners for quantitative geochemical logging of sediment cores: Theory and application. Earth and Planetary Science Letters 274, 423-438. http://dx.doi.org/10.1016/j.epsl.2008.07.054

Woodward, C.A., Gadd, P.S., 2019. The potential power and pitfalls of using the X-ray fluorescence molybdenum incoherent: Coherent scattering ratio as a proxy for sediment organic content. Quatern Int 514, 30-43. http://dx.doi.org/10.1016/i.quaint.2018.11.031

Wray, R.A.L., 2013. Solutional weathering and karstic landscapes on quartz sandstones and quartzite, in: Frumkin, A. (Ed.), Treatise on Geomorphology. Academic Press, San Diego, pp. 463-483.

Wright, H.E., 1967. A square-rod piston sampler for lake sediments. Journal of Sedimentary Research 37, 975-976. http://dx.doi.org/https://doi.org/10.1306/74D71807-2B21-11D7$8648000102 \mathrm{C} 1865 \mathrm{D}$

Zhou, J., Lau, K.-M., 1998. Does a Monsoon Climate Exist over South America? J Climate 11, 10201040.

Zolitschka, B., 1998. A 14,000 year sediment yield record from Western Germany based on annually laminated sediments. Geomorphology 22, 1-17.

Zolitschka, B., Fey, M., Janssen, S., Maidana, N.I., Mayr, C., Wulf, S., Haberzettl, T., Corbella, H., Lücke, A., Ohlendorf, C., Schäbitz, F., 2019. Southern Hemispheric Westerlies control sedimentary processes of Laguna Azul (south-eastern Patagonia, Argentina). The Holocene 29, 403-420. http://dx.doi.org/10.1177/0959683618816446 


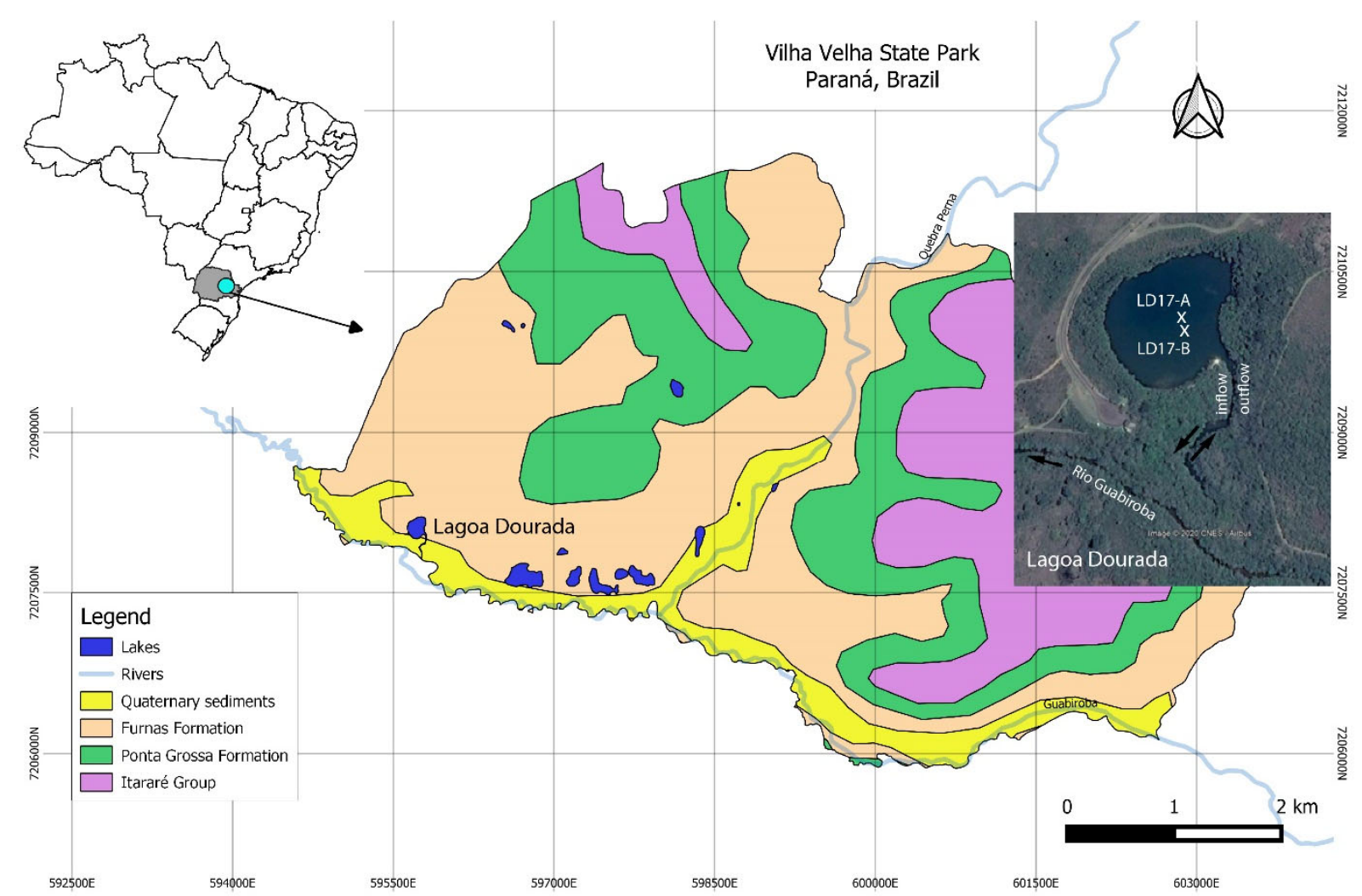

1268 Fig. 1: Location of Lagoa Dourada in Paraná (South Brazil) with a geological map of the Vilha Velha

1269 State Park based on information from "Plano de Manejo Vegetação Parque Estadual Vila Velha"

1270 (Governo do Estado de Paraná, 2004) and an aerial photography of the lake with Rio Guabiroba from

1271 Google Earth. Coring locations LD17-A and LD17-B are marked (X) in the aerial photography.

1272

1273

1274

1275 


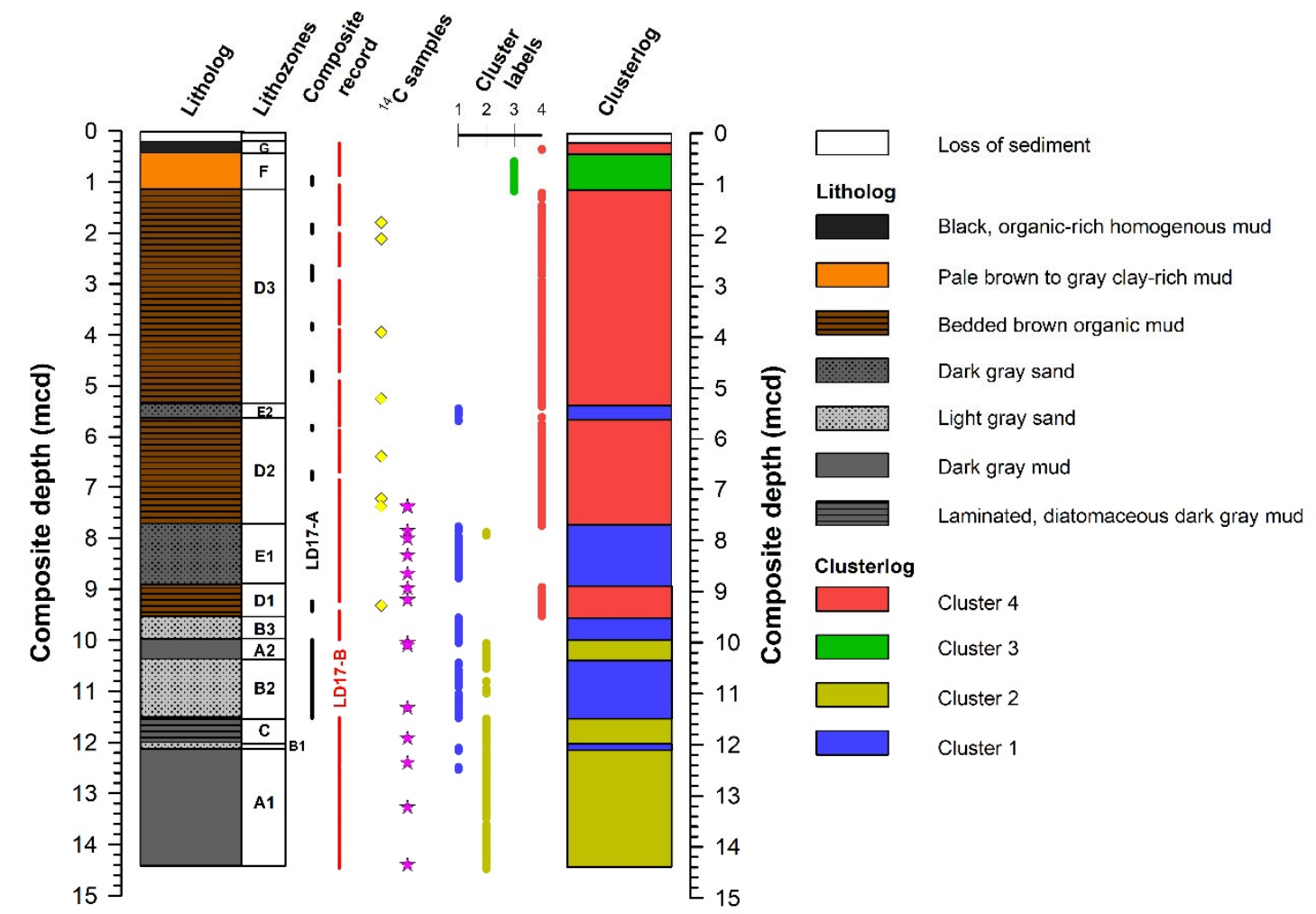

Fig. 2: Litholog (left) of the composite record based on macroscopic and microscopic observations 1278 with lithozones A1 through $\mathrm{G}$, core sections used for the construction of the composite record as well 1279 as positions of samples for radiocarbon $\left({ }^{14} \mathrm{C}\right)$ dating. Radiocarbon ages of terrestrial macrofossils are 1280 shown as yellow diamonds and those on bulk organic matter as pink stars. All data related to ${ }^{14} \mathrm{C}$ 1281 dating are provided with Tab. 1. Clusterlog (right) is based on cluster analysis for comparison. 


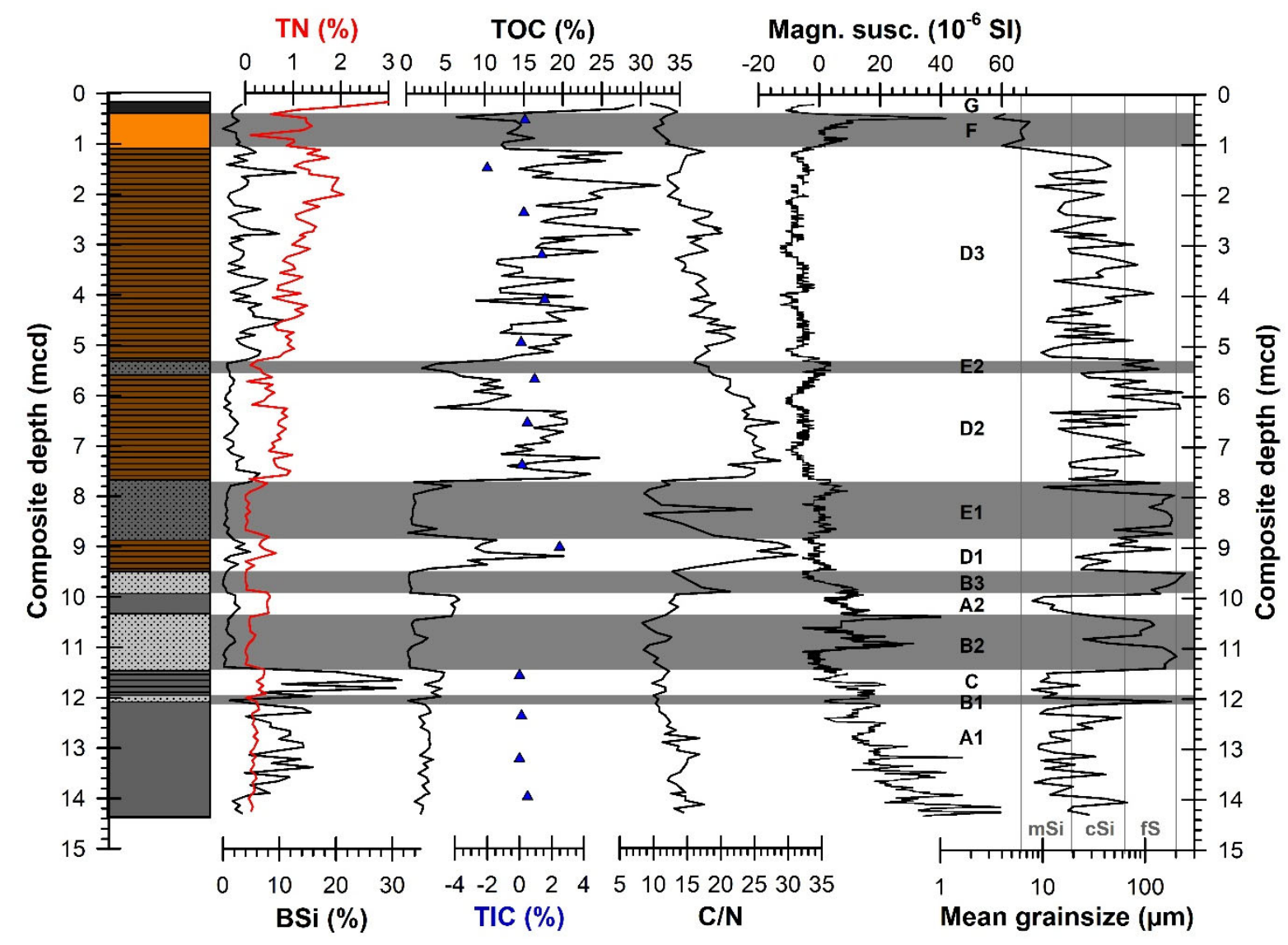

Fig. 3: Litholog with lithozones A1 through G (for legend: cf., Fig. 2) with bulk geochemistry, including 1287 total nitrogen (TN), total organic carbon (TOC), total inorganic carbon (TIC), magnetic susceptibility 1288 (Magn. susc.), biogenic silica (BSi), carbon-to-nitrogen ratio $(\mathrm{C} / \mathrm{N})$ and mean grainsize. Sand horizons 1289 (LZs B and E) and lithozone $F$ are shaded in gray. 
Dominance of organic vs. minerogenic matter Minerogenic Organic

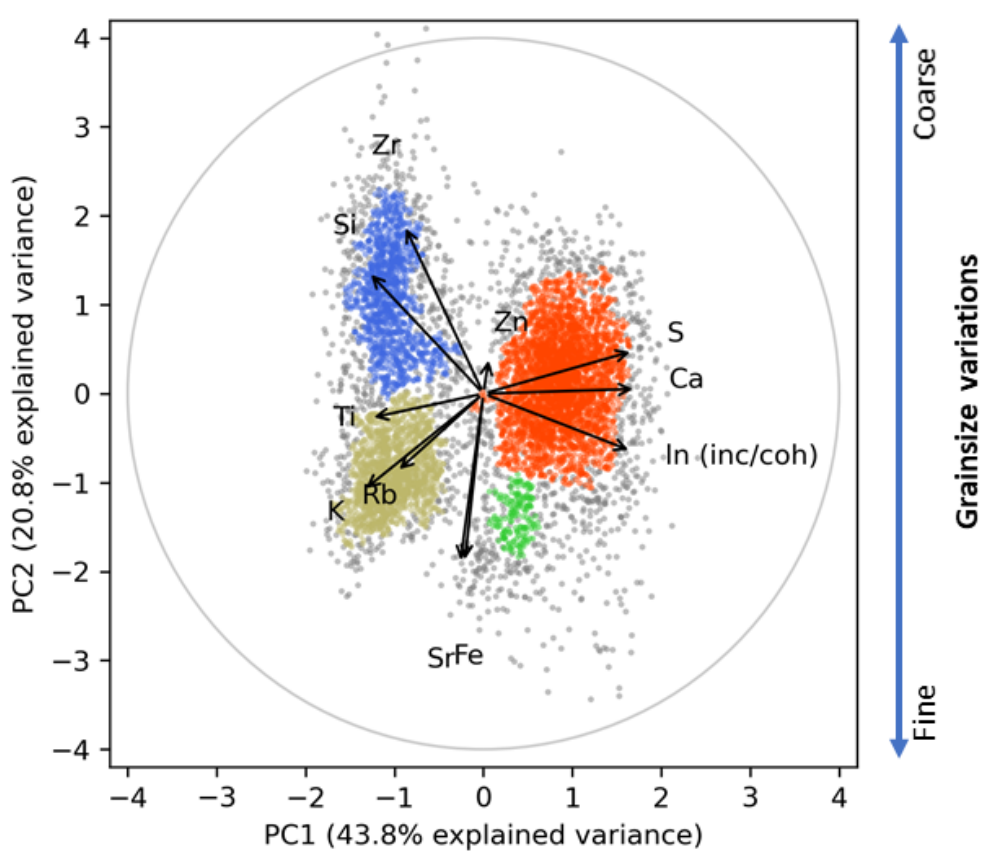

1292 Fig. 4: PCA loadings from homogenized (clr-transformed) elemental intensities obtained by XRF core 1293 scanning. The first two principal components preserve $64.6 \%$ of the total variance. The four determined clusters (Cluster 1-4) are color-coded (for legend: cf., Fig. 2) and data points related to noise are plotted in gray. The circle indicates a value of 1 for the loadings. Interpretations in terms of grainsize variations and dominance of organic vs. minerogenic matter are indicated by blue arrows. 


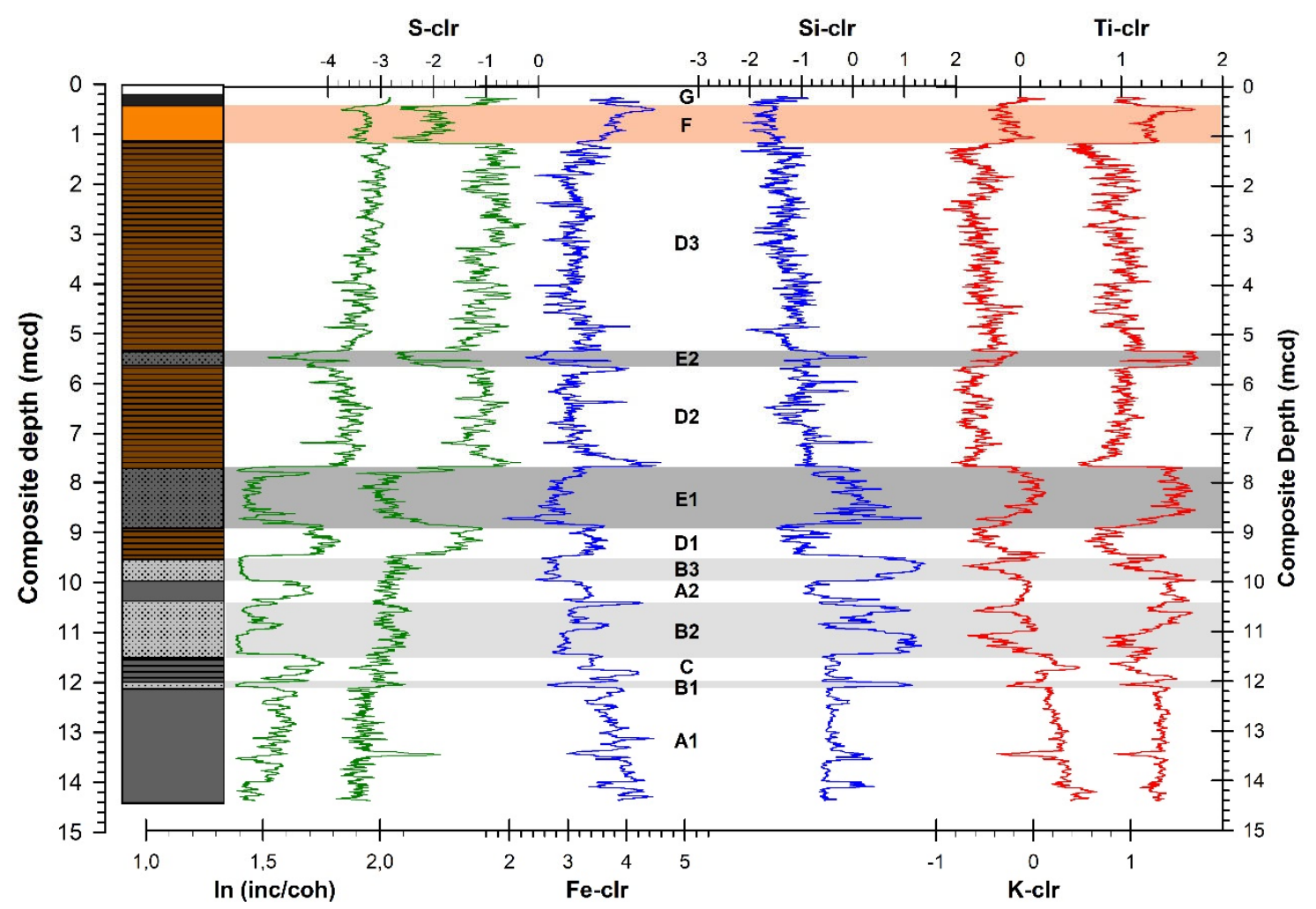

1299 Fig. 5: Litholog with lithozones A1 through G (for legend: cf., Fig. 2) and selected clr-transformed 1300 elemental data obtained by XRF core scanning. Shown are the elements sulphur (S), silica (Si), 1301 titanium (Ti), iron ( $\mathrm{Fe}$ ), potassium (K) and the incoherent/coherent ratio (inc/coh). Sand horizons (LZs $B$ and $E$ ) and lithozone $F$ are shaded in gray. 


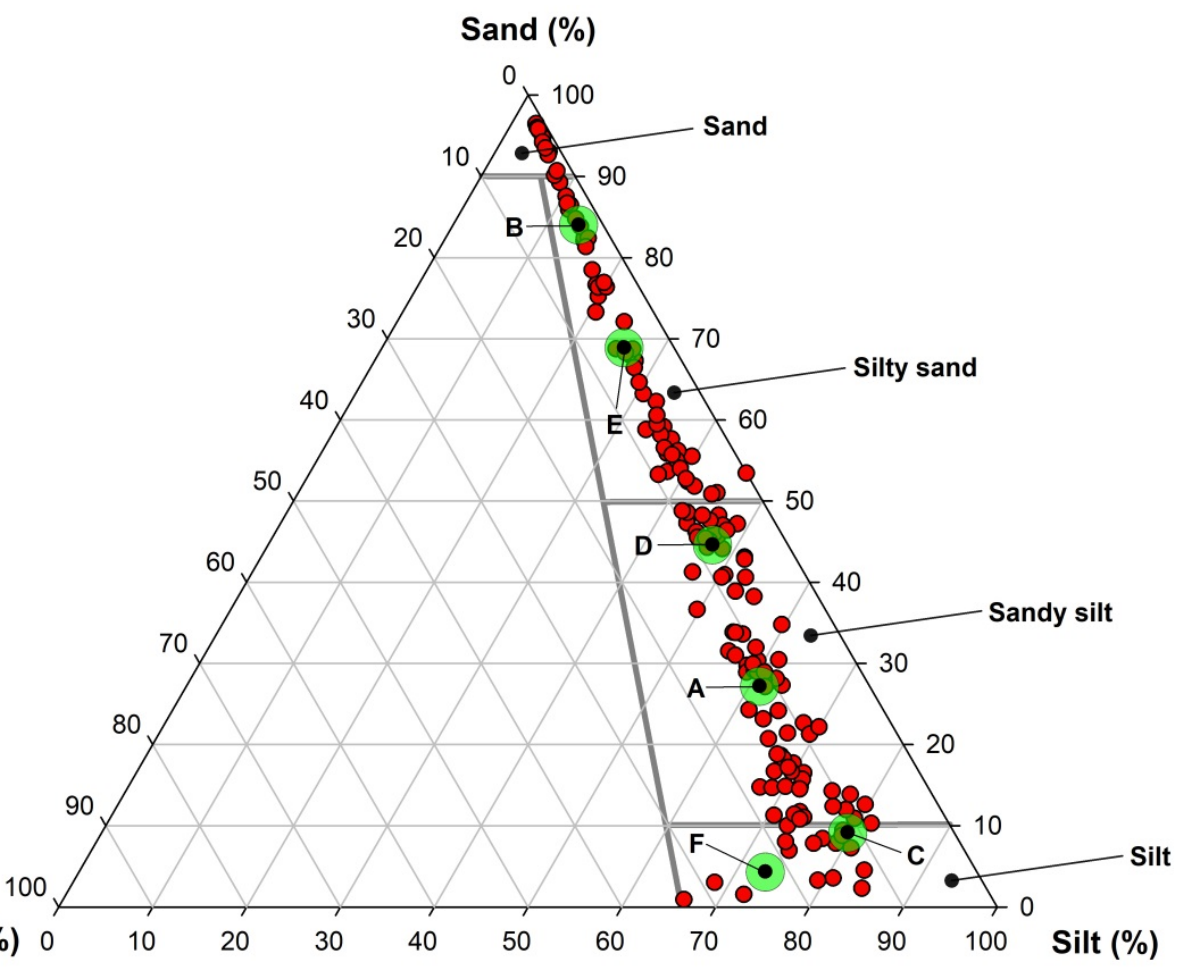

1306 Fig. 6: Ternary grainsize diagram (red dots mark individual samples) with mean grainsize values for lithozones A-F (labeled with the corresponding letter and encircled in green color). 


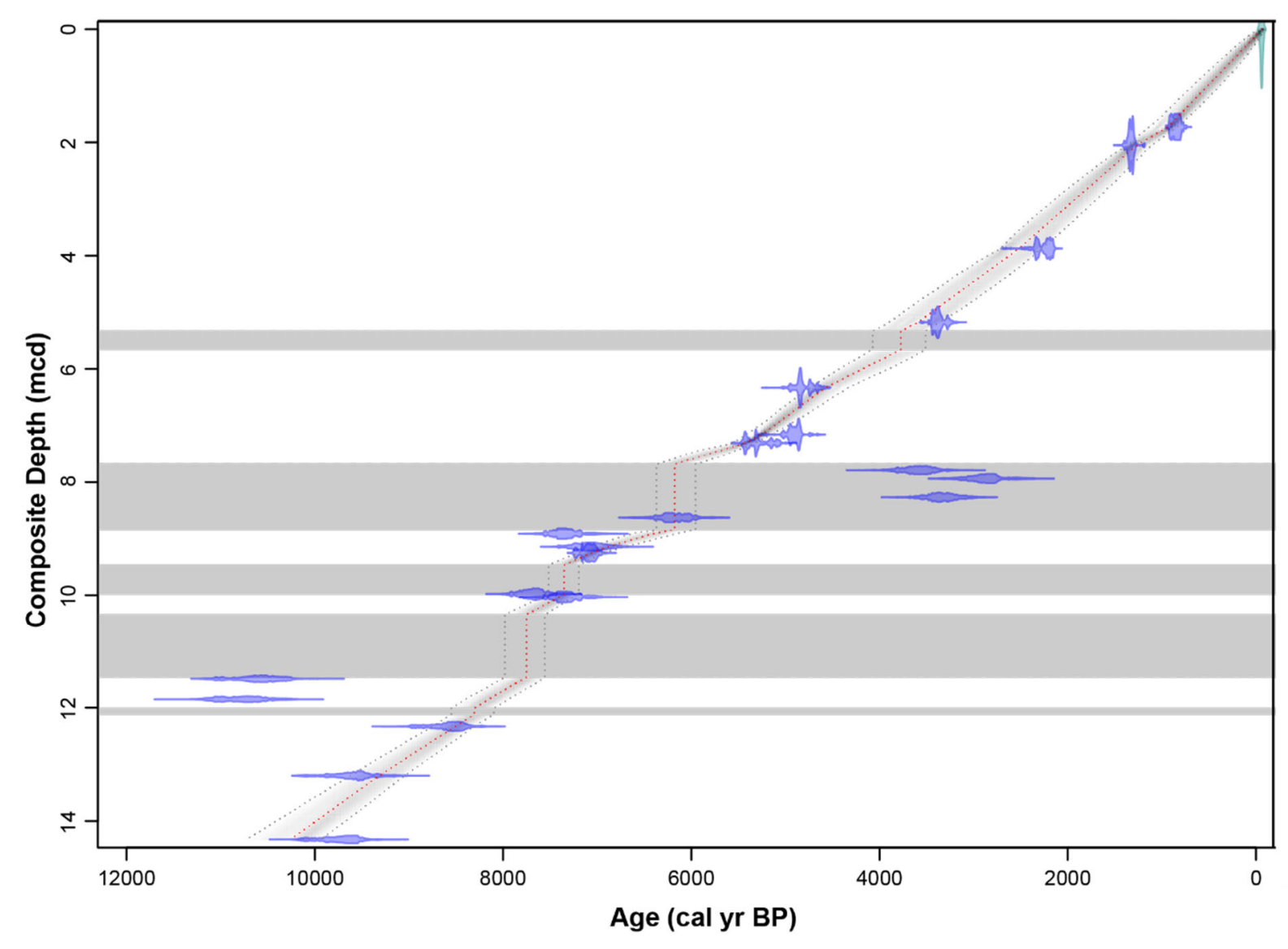

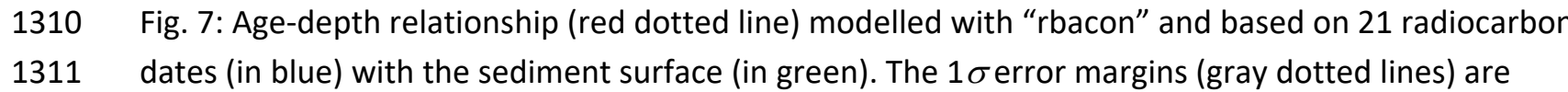
1312 indicated as well as the five sand horizons (gray horizontal bars) excluded from age-depth model 1313 calculations. 


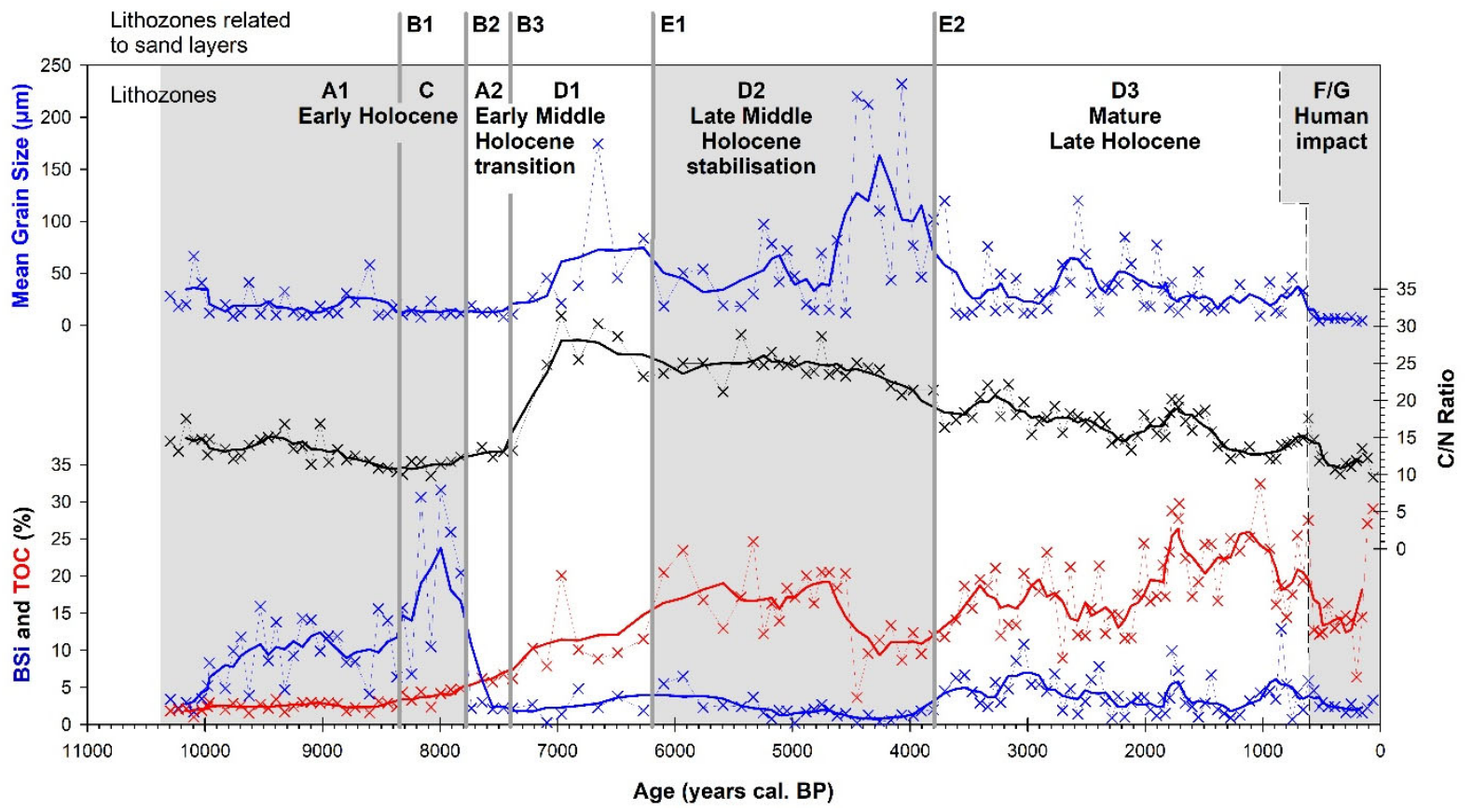

1316 Fig. 8: Selected geochemical data (biogenic silica: BSi; total organic carbon: TOC; carbon-to-nitrogen ratio: $\mathrm{C} / \mathrm{N}$ ratio) are shown together with mean grainsize vs. time. Lithozones and the position of sand horizons (LZs B and E) excluded from age-depth modelling are labelled as well as stratigraphical assignments and human impact. 


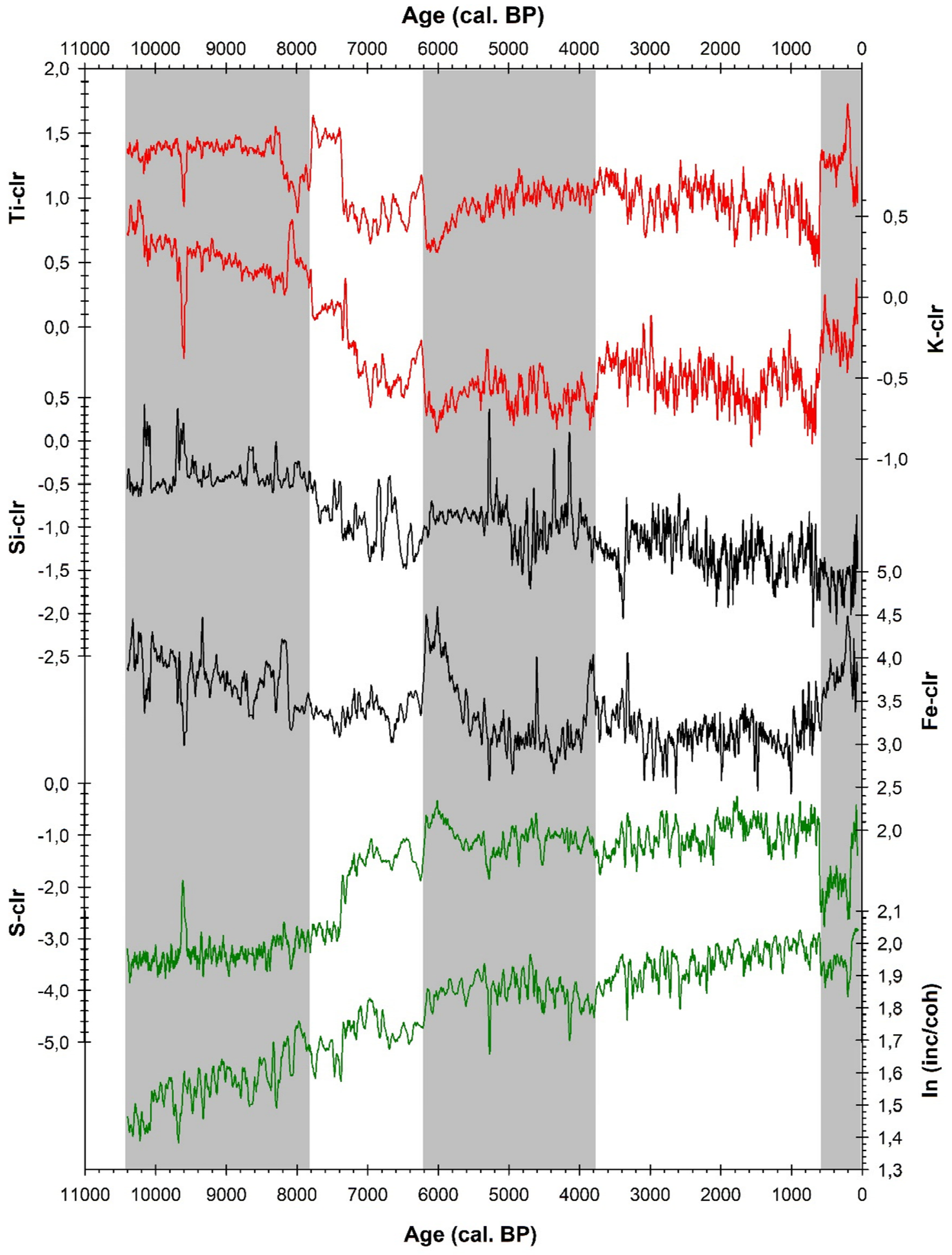

Fig. 9: Selected clr-transformed elemental data obtained by XRF core scanning. Shown are the elements sulphur (S), silica (Si), titanium (Ti), potassium (K), iron ( $\mathrm{Fe}$ ) and the incoherent/coherent ratio (inc/coh) vs. time. Shading as in Fig. 8. 


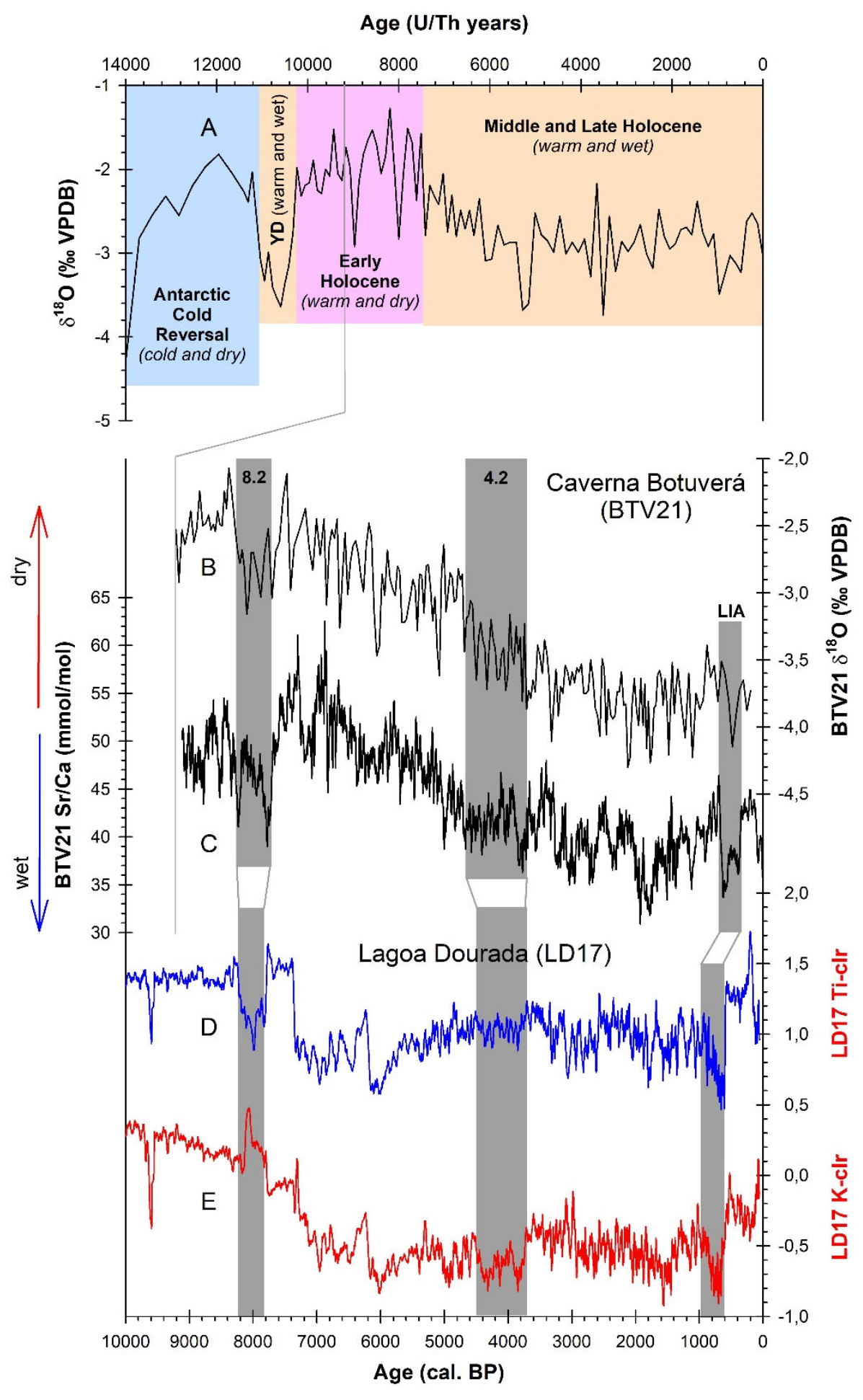

Fig. 10: Comparison of speleothem data from Caverna Botuverá with lacustrine sediment data from Lagoa Dourada. A) Oxygen isotope record from Botuverá speleothem BTV2 focusing on the last 14 ka (Cruz, 2005; Cruz et al., 2005). Climatic conditions are labelled and color-coded (YD: Younger Dryas) and derived from Novello et al. (2017). Note that this time scale is in U/Th years! B) Oxygen isotope record and C) Sr/Ca ratio from Botuverá speleothem BTV21 for the Holocene (Bernal et al., 2016a; Bernal et al., 2016b) with hydroclimatic interpretation (arrows). Additionally, clr-transformed elemental data of $\mathrm{D}$ ) titanium (Ti) and potassium (K) are shown from the sediment record of Lagoa Dourada. The three most prominent Holocene climatic events are marked by vertical gray bars. Note: the chronology for the last millennium of the Lagoa Dourada record is shown with the "rbacon" age-depth model causing a temporal offset for the last millennium - for explanation see the text. All data from Caverna Botuverá were accessed online via the NOAA Paleoclimatology Program on February 18, 2021. 
Tab. 1: Radiocarbon ages with sample depths, sample characteristics as well as reservoir corrections. Ages used for calculation of the reservoir effect are

\begin{tabular}{|c|c|c|c|c|c|c|c|c|c|c|}
\hline $\begin{array}{c}\text { Sample } \\
\text { ID } \\
\text { (LD-) }\end{array}$ & Lab. No. & $\begin{array}{c}\text { Sampled } \\
\text { Core }\end{array}$ & $\begin{array}{l}\text { Section } \\
\text { Depth } \\
\text { (cm) }\end{array}$ & $\begin{array}{l}\text { Composit } \\
\text { Depth } \\
\text { (mcd) }\end{array}$ & $\begin{array}{l}\text { Type of } \\
\text { Sample }\end{array}$ & $\begin{array}{c}\text { Radiocarbon } \\
\text { Age } \\
\text { (BP) }\end{array}$ & \pm & $\begin{array}{l}1 \sigma \text { Range of } \\
\text { Calibrated } \\
\text { Radiocarbon } \\
\text { Ages (cal. BP) }\end{array}$ & $\begin{array}{c}\text { Reservoir } \\
\text { Correction } \\
\text { (yrs) }\end{array}$ & Comments \\
\hline 1 & POZ-119117 & LD17-B2 & $89.5-90.5$ & 1,73 & Macro-fossil & 990 & 30 & $801-916$ & & \\
\hline 2 & POZ-111295 & LD17-B3 & $29-30$ & 2,05 & Macro-fossil & 1470 & 30 & $1300-1351$ & & \\
\hline 3 & UBA-29240 & LD17-B5 & $6.8-6.9$ & 3,87 & Macro-fossil & 2330 & 35 & $2156-2345$ & & \\
\hline 4 & POZ-121537 & LD17-B6 & $41-42$ & 5,18 & Macro-fossil & 3205 & 35 & $3357-3445$ & & \\
\hline 5 & POZ-119118 & LD17-B7 & $56.2-56.6$ & 6,34 & Macro-fossil & 4300 & 35 & $4730-4867$ & & \\
\hline 6 & POZ-107807 & LD17-B8 & 39.1-39.2 & 7,16 & Macro-fossil & 4355 & 35 & 4839-4959 & & \\
\hline 7 & POZ-122526 & LD17-B8 & $53-54$ & 7,30 & Bulk & 9700 & 40 & & 5065 & age used for reservoir correction with LD-8 \\
\hline 8 & POZ-119119 & LD17-B8 & $54.1-54.5$ & 7,31 & Macro-fossil & 4635 & 35 & $5145-5446$ & & \\
\hline 9 & POZ-119120 & LD17-B8 & $55-56$ & 7,32 & Bulk & 9870 & 40 & & 5235 & age used for reservoir correction with LD-8 \\
\hline 10 & POZ-122527 & LD17-B8 & $102-103$ & 7,79 & Bulk & 8530 & 50 & $3398-3821$ & $5150 \pm 100$ & outlier; from sand horizon \\
\hline 11 & POZ-119121 & LD17-B9 & 10-11 & 7,94 & Bulk & 7930 & 50 & $2723-3134$ & $5150 \pm 100$ & outlier; from sand horizon \\
\hline 12 & POZ-116232 & LD17-B9 & $43-44$ & 8,27 & Bulk & 8330 & 40 & $3164-3558$ & $5150 \pm 100$ & outlier; from sand horizon \\
\hline 13 & POZ-122528 & LD17-B9 & $79-80$ & 8,63 & Bulk & 10590 & 50 & $5995-6383$ & $5150 \pm 100$ & from sand horizon \\
\hline 14 & POZ-119122 & LD17-B10 & $41-42$ & 8,92 & Bulk & 11630 & 60 & $7169-7555$ & $5150 \pm 100$ & \\
\hline 15 & POZ-111296 & LD17-B10 & $64-65$ & 9,15 & Bulk & 11380 & 60 & $6890-7265$ & $5150 \pm 100$ & \\
\hline 16 & UBA-29241 & LD17-B10Liv & 9.3-9.8 & 9,24 & Macro-fossil & 6235 & 35 & $7012-7163$ & & \\
\hline 17 & POZ-107808 & LD17-B10Liv & $82-83$ & 9,98 & Bulk & 12020 & 60 & $7518-7840$ & $5150 \pm 100$ & \\
\hline 18 & POZ-119188 & LD17-A11 & $29-30$ & 10,02 & Bulk & 11620 & 50 & $7167-7485$ & $5150 \pm 100$ & \\
\hline 19 & POZ-107809 & LD17-B11 & $96-97$ & 11,49 & Bulk & 14540 & 80 & $10261-11083$ & $5150 \pm 100$ & outlier; from sand horizon \\
\hline 20 & POZ-116234 & LD17-B12 & $42-43$ & 11,85 & Bulk & 14660 & 80 & $10513-11083$ & $5150 \pm 100$ & outlier \\
\hline 21 & POZ-111297 & LD17-B12 & $90-91$ & 12,32 & Bulk & 12930 & 60 & 8373-8769 & $5150 \pm 100$ & \\
\hline 22 & POZ-107810 & LD17-B 13 & $76-77$ & 13,15 & Bulk & 13750 & 70 & $9318-9889$ & $5150 \pm 100$ & \\
\hline 23 & POZ-107815 & LD17-B 14 & $97-98$ & 14,33 & Bulk & 13850 & 70 & $9486-10109$ & $5150 \pm 100$ & \\
\hline & \multirow{2}{*}{\multicolumn{4}{|c|}{ POZ: Poznań Radiocarbon Laboratory, Poland }} & & & & & & \\
\hline & & & & & & & & & & \\
\hline & \multicolumn{6}{|c|}{ UBA: ${ }^{14}$ Chrono Centre at Queen's University Belfast, Northern Ireland } & & & & \\
\hline
\end{tabular}



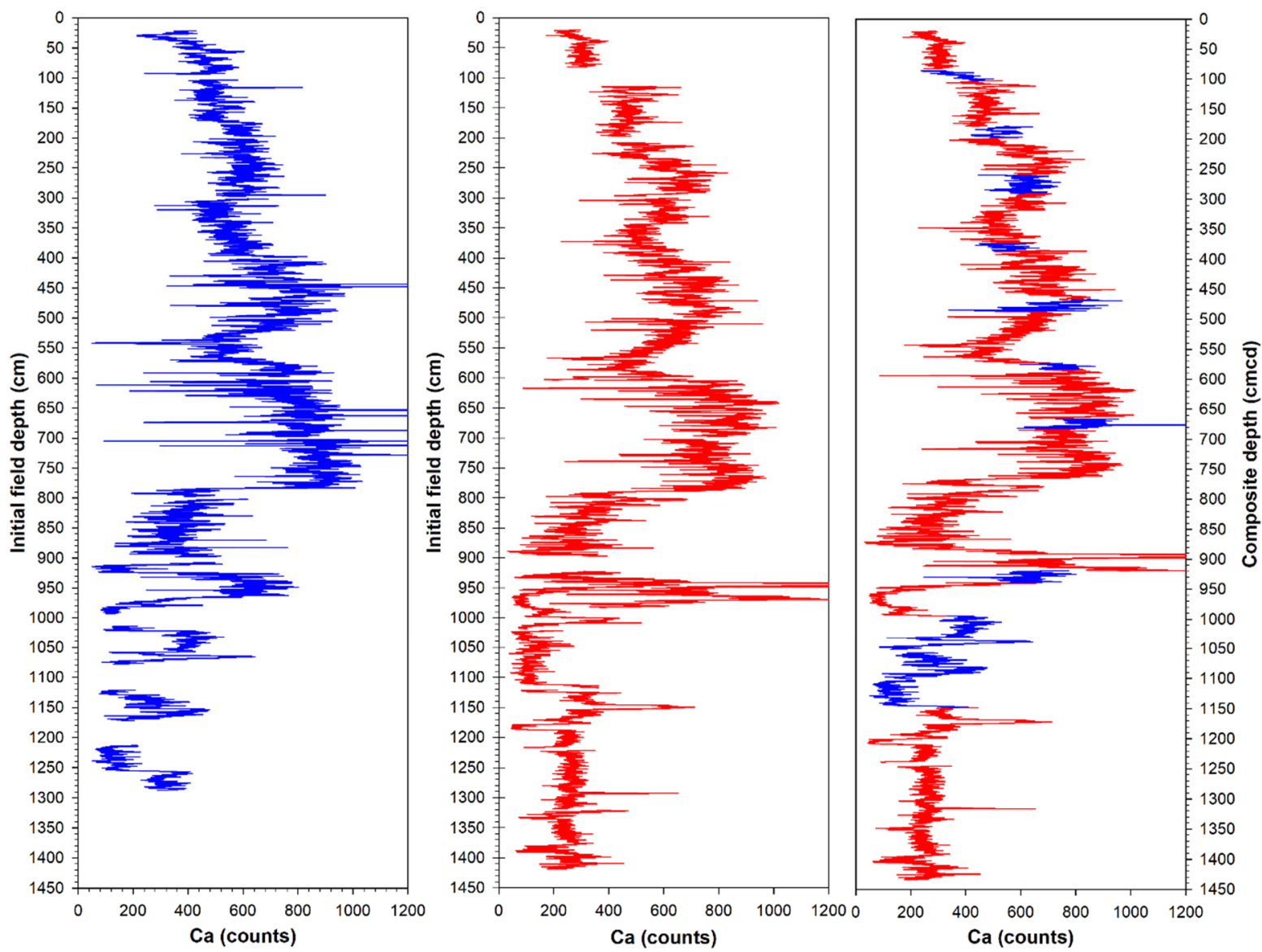

Fig. S1: Ca counts obtained by XRF core scanning vs. field depths for sediment cores LD17-A (blue) and LD17-B (red) as well as for the merged composite record, now on a composite depth scale and displayed in centimeter composite depth ( $\mathrm{cmcd}$ ). 


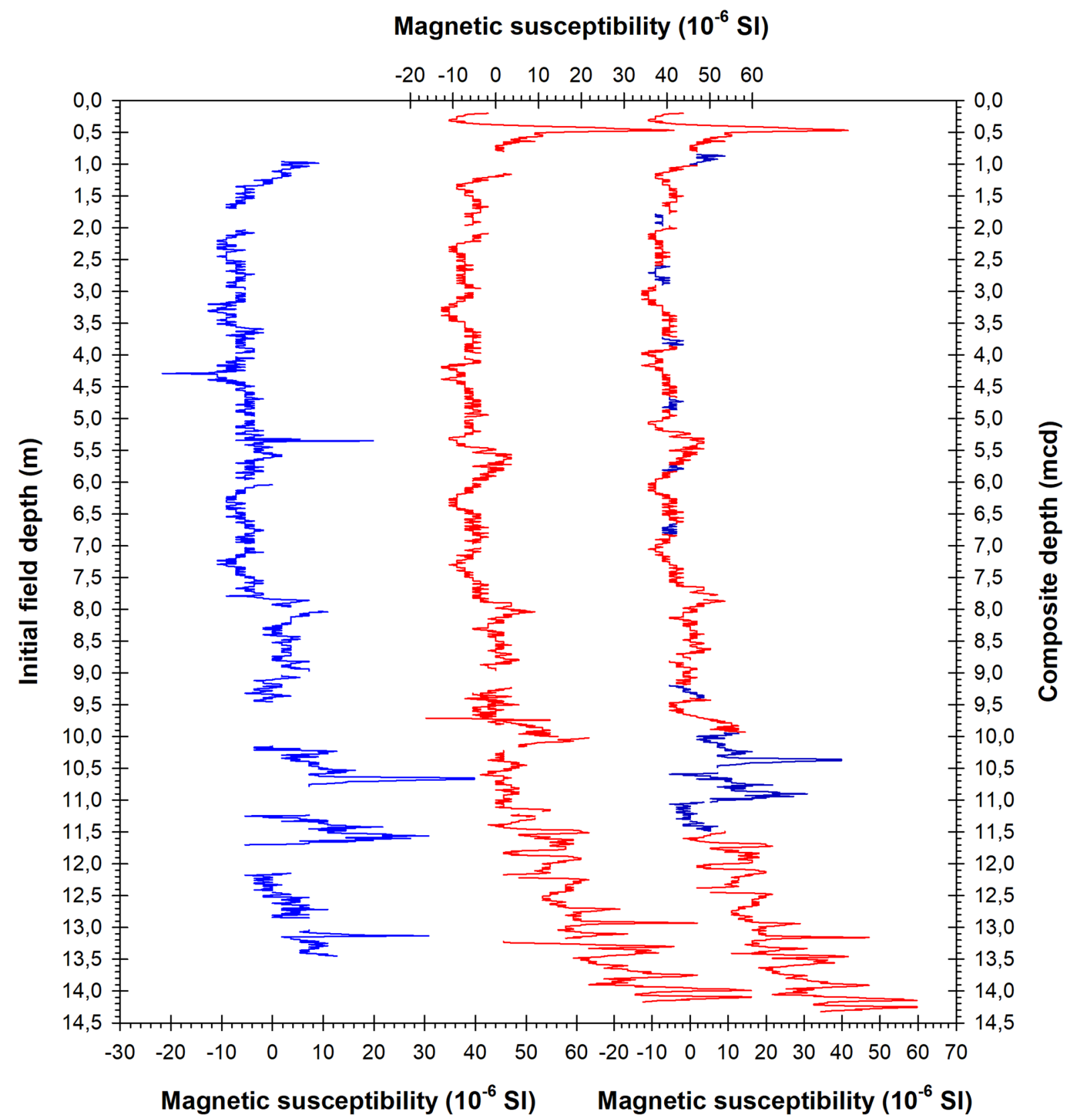

Fig. S2: Magnetic susceptibility versus field depths for sediment cores LD17-A (blue) and LD17-B (red) as well as for the merged composite record displayed on a composite depth scale in meter composite depth (mcd). Correlation of LD17-A and LD17-B is not based on the magnetic susceptibility data shown but on Ca data (cf., Fig. S1). 


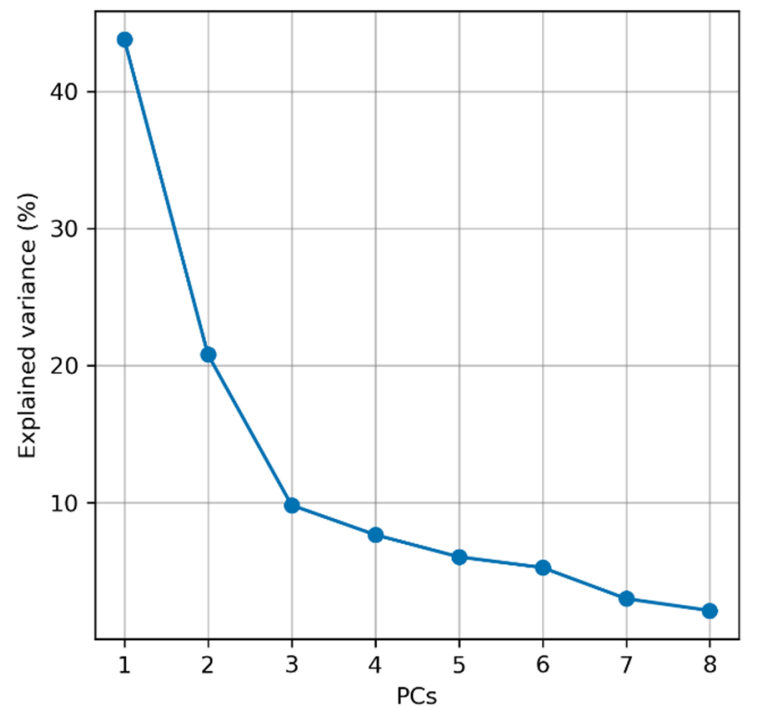

1354

1355 Fig. S3: Scree plot of the explained variance ratio for all principal components (PCs) based on normalized (clr-transformed) and standardized elemental intensities obtained by XRF core scanning

1357 (cf., Fig. 4).

1358 


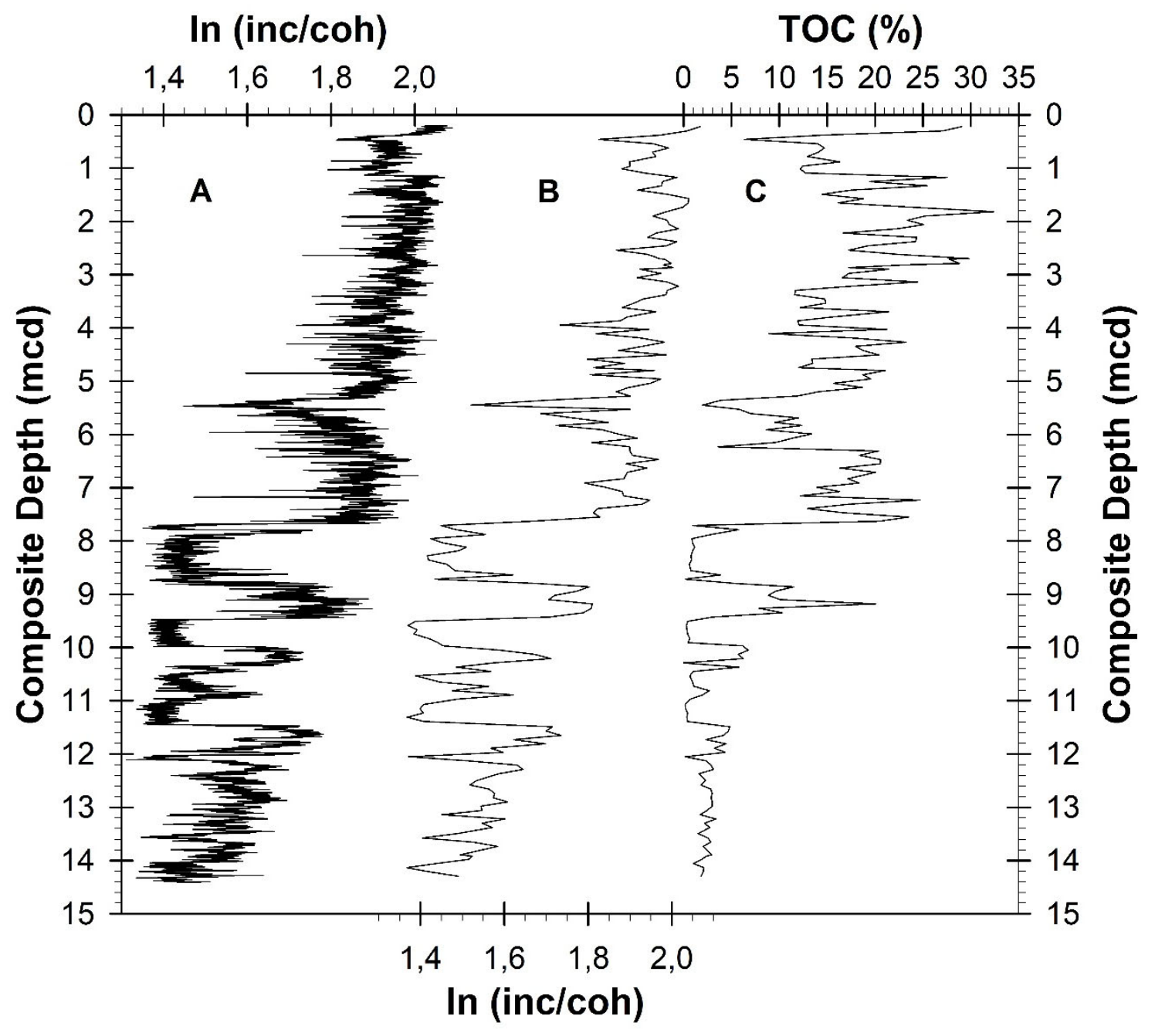

1361 Fig. S4: Organic matter for the sediment record from Lagoa Dourada. A) High resolution (2 mm) 1362 record of the $\mathrm{In} \mathrm{inc} / \mathrm{coh}$ ratio; B) Same ratio with resolution reduced to $8 \mathrm{~cm}$; C) Low resolution $1363(8 \mathrm{~cm})$ total organic carbon (TOC) record. Correlation between B and C: $r=0.88$. 


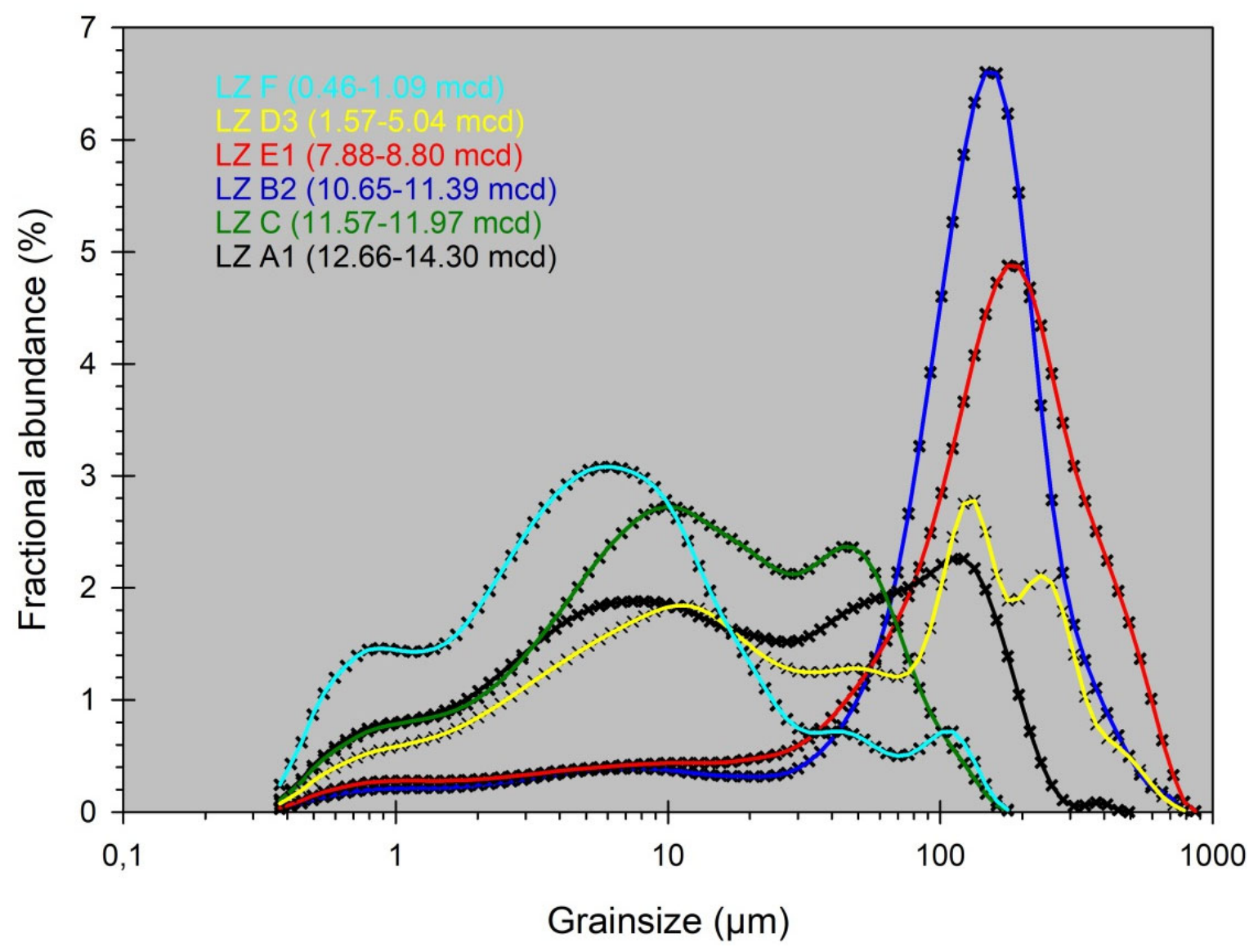

Fig. S5: Grainsize frequency histograms of mean distributions for selected lithozones. 


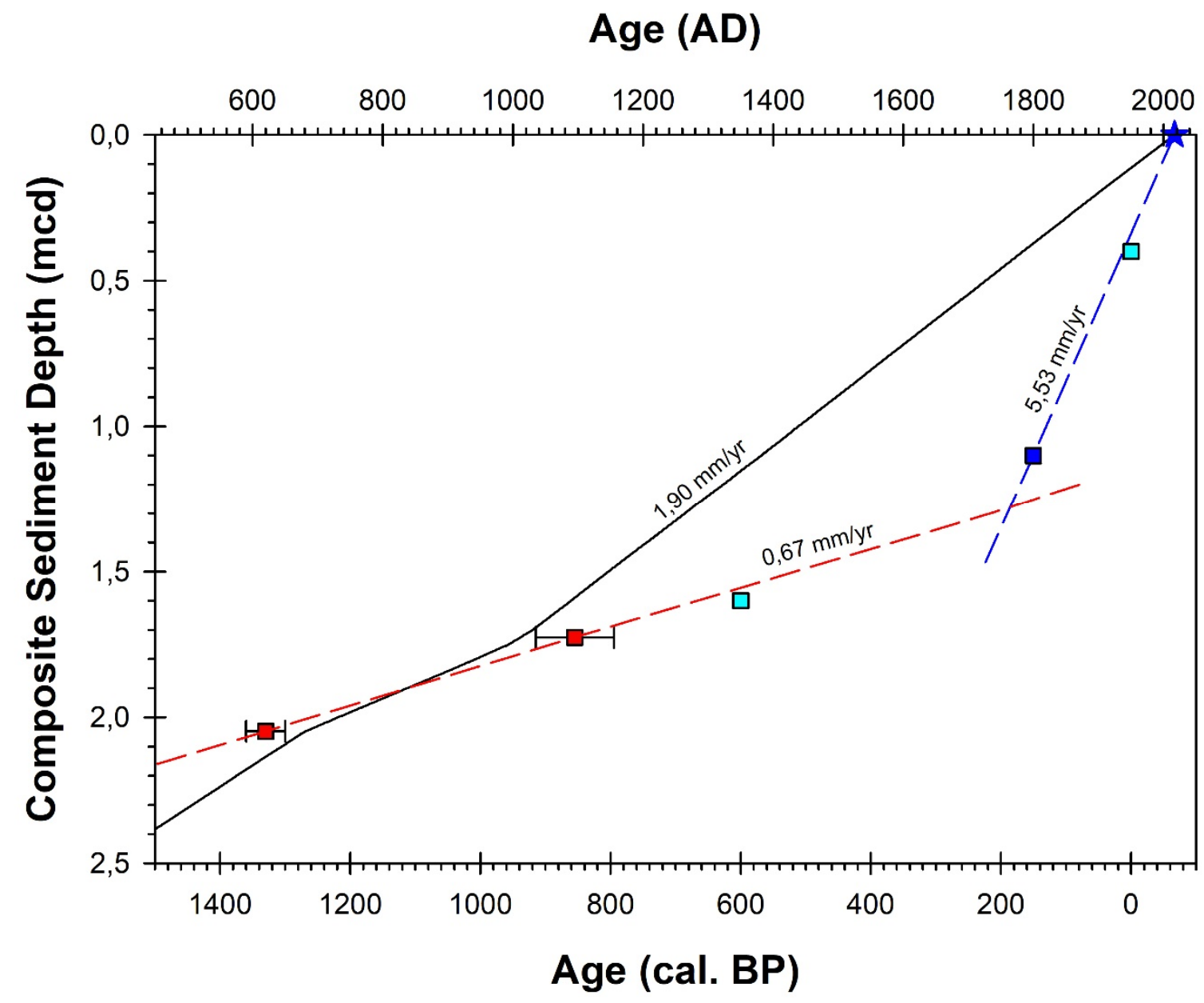

1370 Fig. S6: Modified chronology for the last 1500 years. On display are the "rbacon" age-depth model 1371 (black line), the two uppermost radiocarbon ages (red squares) with a linear sedimentation rate 1372 based on these two dates only (red dashed line) and an age for the onset of land-use change at AD $1800 \pm 50$ years ( 150 cal. BP; blue square) with a linear sedimentation rate (blue dashed line) calculated for this historical date and the sediment surface of the year of coring, i.e. AD 2017 (-63 cal. BP) blue star). Values provided in $\mathrm{mm} / \mathrm{yr}$ are respective linear sedimentation rates. Additionally, two data points are shown (cyan): (1) AD 1953 (-3 cal. BP) at $0.4 \mathrm{mcd}$, the year of establishing the Vila Velha State Park as indicated by returning organic sediments (onset of LZ G) coinciding with the calculated linear sedimentation rate; (2) The change in elemental data at $1.6 \mathrm{mcd}$ interpreted as the onset of the LIA (see text for explanation) and its timing of AD 1300 (650 cal. BP) as based on linearly extrapolating the radiocarbon-based sedimentation rates. 
Tab. S1: Correlation coefficients for 20 elements as well as incoherent (inc) and coherent (coh) radiation analyzed with the XRF core scanner for sediment cores LD-B6 (organic) and LD-B12 (minerogenic). Both cores were $97 \mathrm{~cm}$ in length, scanned every $2 \mathrm{~mm}$ and consist of 486 individual data points. Each core scanning was repeated five times. Only elements with a high positive correlation of $r>0.8$ for at least one of the two core sections (shaded in gray) were selected for further statistical treatment.

LD-B6
Element

Element

Mean counts for each element

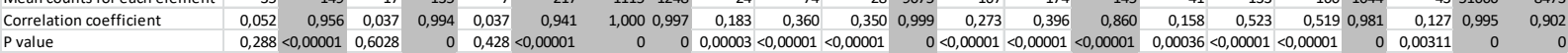

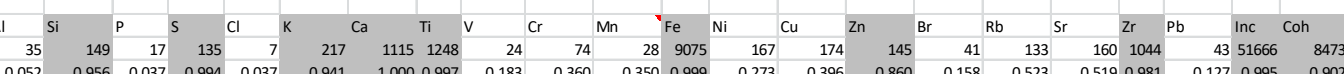

LD-B12

Element

Mean counts for each element

Correlation coefficient

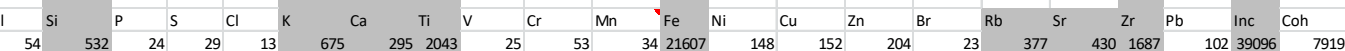

